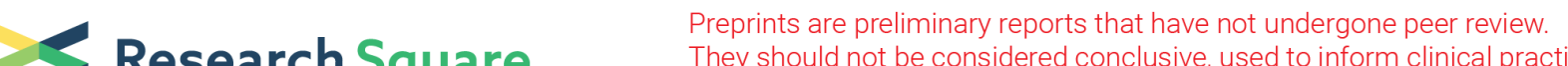 $\begin{array}{ll}\text { Research Square } & \text { They should not be considered conclusive, used to inform clinical practice, } \\ \text { or referenced by the media as validated information. }\end{array}$
}

\section{Assessment of Spatiotemporal Variability and Trend Analysis of Reference Crop Evapotranspiration for the southern region of Peninsular India}

Jayashree Tenkila Ramachandra ( $\boldsymbol{\sim}$ jayastr@gmail.com )

Manipal Institute of Technology https://orcid.org/0000-0001-7910-8978

Subba Reddy Nandanavana Veerappa

Manipal Institute of Technology

Dinesh Acharya Udupi

Manipal Institute of Technology

\section{Research Article}

Keywords: Reference Crop Evapotranspiration, FAO Penman-Monteith, agro-climatic zones, climate variables, spatial variability, temporal variability, trend analysis.

Posted Date: March 30th, 2021

DOl: https://doi.org/10.21203/rs.3.rs-330856/v1

License: (9) This work is licensed under a Creative Commons Attribution 4.0 International License. Read Full License

Version of Record: A version of this preprint was published at Environmental Science and Pollution Research on August 18th, 2021. See the published version at https://doi.org/10.1007/s11356-021-159580 . 


\section{Abstract}

Accurate estimation of reference evapotranspiration $\left(\mathrm{ET}_{0}\right)$ is an essential requirement for water resource management and scheduling agricultural activities. Several empirical methods have been employed in estimating $\mathrm{ET}_{0}$ across diverse climate regimes over the past decades. The Python implementation for estimation of daily and monthly $\mathrm{ET}_{0}$ values of representative stations of ten agro-climatic zones of Karnataka from 1979 through 2014 using the standard FAO Penman-Monteith method was carried out. The assessment of temporal and spatial variability of monthly $\mathrm{ET}_{0}$ values across the various agroclimatic zones done by the various statistical measures revealed that the variation in spatial $\mathrm{ET}_{0}$ values was higher than temporal indicating major differentiation of $\mathrm{ET}_{0}$ values was with respect to the stations rather than years under study. The non-parametric Mann-Kendall test conducted at $1 \%$ significance level on the annual $\mathrm{ET}_{0}$ values revealed that statistically significant increasing trend was observed for all the ten stations during the study period. The trend test conducted on the climate variables like mean air temperature, wind speed, relative humidity and solar radiation signify their influence the annual $\mathrm{ET}_{0}$ values. The magnitude changes in the trends detected by the Theil Sen's slope indicated that increasing values of mean temperature, solar radiation and decreasing values of relative humidity predominantly contributed to the annual upward trend in $\mathrm{ET}_{0}$ values for the 10 stations. A trivial impact of wind speed on annual $\mathrm{ET}_{0}$ values was observed for the stations. Kalburgi and Udupi stations exhibited positive $\mathrm{ET}_{0}$ trend with the highest and lowest annual values among ten stations.

\section{Introduction}

Evapotranspiration (ET) is a major tool in computing water balance and its requirements for plants. It is also responsible for inducing cloud formation by returning water vapour to the atmosphere and thus has a crucial role in the hydrologic cycle. ET is the combination of two separate processes whereby water is transferred from land to atmosphere through evaporation from wet surfaces and by transpiration from vegetation. The ET is a complicated process as it is influenced by various factors related to climate, vegetation, and soil moisture. The ET process has been used in many domains, including irrigation design and scheduling for agricultural applications, meteorological and hydrological applications.

Reference evapotranspiration is a significant parameter in the estimation of crop water requirement and irrigation scheduling. The crop water need or crop water requirement (ET crop) is defined as the amount of water consumed to meet the water loss through evapotranspiration. That is, it is the amount of water needed by the various crops for its survival, growth and development, which mainly depends on the climate, crop type and the different growth stages of the crop. The irrigation scheduling based on ET is of major concern for sustainable agricultural development across the world. Hence, it is necessary to quantify accurate reference evapotranspiration values by considering different agro-climatic conditions for the best irrigation planning and management practices. 
The concept of reference evapotranspiration or reference crop evapotranspiration ( $\left.E T_{0}\right)$ was introduced to avoid the ambiguities presented in the definition of evapotranspiration. $\mathrm{ET}_{0}$ refers explicitly to the $\mathrm{ET}$ from a well-watered hypothetical green grass free of stress and diseases. Reference evapotranspiration is defined as "the rate of evapotranspiration from a hypothetical reference crop with an assumed crop height of $0.12 \mathrm{~m}$ (4.72 in), a fixed surface resistance of $70 \mathrm{sec} \mathrm{m}-1$ (70 sec 3.2ft-1) and an albedo of 0.23 , closely resembling the evapotranspiration from an extensive surface of green grass of uniform height, actively growing, well-watered, and completely shading the ground". $\mathrm{ET}_{0}$ is the rate at which water vapour is evaporated from a hypothetical green grass with abundant soil moisture supply (Allen et al. 1996).

The $\mathrm{ET}_{0}$ computation requires both meteorological and non-meteorological data of climate stations. The estimated $\mathrm{ET}_{0}$ is a meteorological parameter that provides an estimate of available water demands, which are essential for irrigation scheduling systems. Accurate computation of $\mathrm{ET}_{0}$ is crucial for managing irrigation activities. The direct method of quantifying the $\mathrm{ET}_{0}$ using lysimetric approach is expensive, time consuming and lacks precision. Among the several existing empirical methods, the Food and Agriculture Organization (FAO) adopted the Penman-Monteith equation as the standard one, which can work in a wide variety of meteorological conditions across the world.

The FAO-56 P-M method was found to be the most preferred and desirable indirect approach for accurate estimation of $\mathrm{ET}_{0}$ and evaluation of other empirical models (Allen et al. 1998; Nandagiri and Kovoor 2006; Heydari et al. 2013; Pandey and Pandey 2016; Tabari et al. 2013; Lo' pez-Urrea et al. 2006). The FAO-56 P-M method was used in estimation of $\mathrm{ET}_{0}$ with more precision and the values were further used to assess both temporal and spatial variabilities for 18 climate stations in Poland for the duration 19712010 (Łabedzki et al. 2014). Similarly, many researchers have carried out the trend analysis of $\mathrm{ET}_{0}$ values employing the standard FAO-56 P-M method (Hossein Tabari et al. 2011; Liu and Zhang 2013; Bandyopadhyay et al. 2009; Jhajharia et al. 2012).

Several research works have been conducted to demonstrate widespread climatic variations in view of trends of annual $\mathrm{ET}_{0}$ values and the corresponding climatic variables which influence the $\mathrm{ET}_{0}$. The trends of the seasonal (April-September) and monthly reference evapotranspiration time series were analysed with linear regression during 1971-2010 for the climatic conditions of Poland ( $Ł a b e d z k i$ et al. 2014). It was observed that considerable increase in $\mathrm{ET}_{0}$ values were due to the increasing trends of air temperature and sunshine hours. (Xiaoli Gao et al. 2016) demonstrated the decreasing trends of $\mathrm{ET}_{0}$ values for the annual and seasonal time series for the middle, north-western, and south-western areas of Guizhou Province in China. An increasing trend of annual $\mathrm{ET}_{0}$ values were observed in the western area of the country. The duration of sunshine hours was the key factor for these ascending/descending trends. (Tabari et al. 2011) examined the annual, seasonal and monthly trends of FAO P-M computed ET 0 values using Mann-Kendall test and Sen's slope estimation methods for 20 meteorological stations of western Iran during 1966-2005. An upward trend in annual $\mathrm{ET}_{0}$ values in most of the stations in western and north-western parts of Iran were observed for the study period. On the seasonal scale, an increasing trend 
in $\mathrm{ET}_{0}$ values were found in winter and summer which are mainly caused by the rise in atmospheric temperature. The highest and the lowest number of climate stations with notable trends were seen in the months of February and November respectively.

The study carried out for the 75 stations of Tibetan Plateau for the period 1970 to 2009 demonstrated a downward trend in $\mathrm{ET}_{0}$ values across the entire plateau (Xie and Zhu 2013). The temporal trend analysis carried out on the climate variables showed the upward trends in mean air temperature and actual vapour pressure, while wind speed and net radiation witnessed a downward trend. The changes in wind speed, net radiation and actual vapour pressure imposed a negative influence on $\mathrm{ET}_{0}$ values whereas mean temperature showed positive effect on $\mathrm{ET}_{0}$ values. According to the Mann-Kendall test results observed on 12 climate stations of Serbia, the highest increasing trend in $\mathrm{ET}_{0}$ values were detected in summer season and on the annual time scale, considerable positive trends were found in most of the stations (Gocic and Trajkovic 2014). The temporal trends of FAO P-M ET 0 values were investigated for 20 stations in north western part of Iran over a period of 22 years (1986-2007) using Mann-Kendall test and Sen's slope estimator on monthly, seasonal and annual time scales (Azizzadeh and Javan 2015). Most of the stations under study showed a positive trend on a monthly scale. No significant downward $\mathrm{ET}_{0}$ trends were noted in seasonal and annual time scales.

The mean monthly trends of various climatic parameters including $\mathrm{ET}_{0}$ for the period of 24 years (19852009) were investigated for Sikkim state in India using Man-Kendall test. A positive trend has been observed for net radiation and air temperature values in the initial period of the years under study. Vapour pressure deficit and precipitation exhibited a negative trend throughout the year. A declining trend was found in sunshine duration, vapour pressure deficit and $\mathrm{ET}_{0}$ values between the months of March to May and June to November (Yadav et al. 2016). The spatial and temporal trend analysis carried out using Mann-Kendall and Sen's method for 22 stations across Madagascar for the period of 1980-2010 revealed that the highest and the lowest $\mathrm{ET}_{0}$ values observed in the western semi -arid regions and humid eastern regions respectively (Djaman et al. 2018). An upward trend in annual total $\mathrm{ET}_{0}$ values in few stations and no steady trends on monthly scale were noted during the study period.

(Liu et al. 2020) explored the temporal trend analysis of FAO P-M computed $\mathrm{ET}_{0}$ values for 46 climate stations between 1961 and 2017. The non-parametric Mann-Kendall test revealed an upward trend in $\mathrm{ET}_{0}$ values from 1961 to 2017, with most substantial increase observed in winter season. However, a downward trend was observed in 1988. On spatial scale, the multiyear average $\mathrm{ET}_{0}$ values showed an increasing trend from east to west part of the study area. The trends and their magnitudes of climatic variables including the $\mathrm{P}-\mathrm{M}$ computed $\mathrm{ET}_{0}$ values for the 3 stations located in the Tons River Basin in Central India was investigated using Mann-Kendall test and Sen's slope methods (Pandey and Pandey 2013). The annual and seasonal $\mathrm{ET}_{0}$ values exhibited a declining trend in all the stations under study. The monthly $\mathrm{ET}_{0}$ series showed a significant decreasing trend in all the months except August, September and October. The climatic variables such as air temperature and relative humidity exhibited a 
positive trend while the wind speed showed negative trends in monthly, seasonal and annual timescales. The trends of seasonal and annual $\mathrm{ET}_{0}$ over the period 1984-2017 were analysed in the Senegal river basin using the Mann- Kendall test and Sen's slope methods (Ndiaye et al. 2020). An increasing annual and seasonal (dry season) $\mathrm{ET}_{0}$ trend were found in majority of the stations for the study period. A substantial drop in $\mathrm{ET}_{0}$ trend in a particular region was mainly due to decrease in wind speed and rise in relative humidity values.

In the recent past, researchers have reported that the estimation of $\mathrm{ET}_{0}$ for Indian climatic zone using FAO-56 P-M method gave accurate results when compared to other empirical methods (Mohan 1991; Kashyap and Panda 2001; Singandhupe. and Sethi 2004; George et al. 2002; Jhajharia et al. 2004; Singandhupe and Sethi 2005; Murugappan et al. 2011; Poddar et al. 2018). The estimation of $\mathrm{ET}_{0}$ was done for five different agro-climatic zones of Madhya Pradesh using FAO-56 P-M method via Aquacrop model software (Yadav et al. 2017). Thus, most of the most researchers / experts across the world prefer the FAO-56 P-M method due to its suitability for a wide-range of climate conditions. The significant downward annual trend of $\mathrm{ET}_{0}$, wind speed, and net radiation, an increasing trend on mean air temperature and actual vapour pressure were observed in Tibetan Plateau (Xie and Zhu, 2013).

Karnataka is the largest state in south-western part of India. It comprises of various agro-climatic zones with diverse climate conditions, which supports the raising of varieties of crops including cash crops. The primary occupation of rural Karnataka is agriculture and the farmers cultivate variety of crops. Agriculture is the most essential sector of Karnataka state's economy and characterized by both irrigated and drought prone regions. Hence, a large portion of the cultivable land in Karnataka are rain fed and the rest use ground water resources with severe agro-climatic constraints. Karnataka is considered as the study area in the present research work, as the water management is one of the most important component for irrigation and ultimately yield prediction in the state.

The objective of the present study is to estimate the daily $\mathrm{ET}_{0}$ values of ten agro-climatic zones of Karnataka State, India for a duration of 35 years (1979 to 2014) using FAO-56 P-M method. The temporal and spatial variability of the agro-climatic zones of Karnataka on monthly basis is assessed and the annual trends of $\mathrm{ET}_{0}$ corresponding to different climate variables were examined using Mann-Kendall and Sen's slope estimator methods.

\section{Methodology}

The outline of the research work is briefed in Fig. 1. The input variables like temperature, relative humidity, wind speed, sunshine hours and solar radiation intensity need to be collected. Karnataka state includes ten agro-climatic zones comprising of varied agriculture practices that contributes to the economy of the state. Hence, the estimation of $\mathrm{ET}_{0}$ and the assessment of spatial and temporal variables that ultimately influence the irrigational requirements and crop yield is the need of the hour. The sequential protocol of 
$\mathrm{ET}_{0}$ estimation and assessment of the temporal and spatial variability of $\mathrm{ET}_{0}$ is shown in Fig. 2. The description of the study area and the climate data collection are presented in the following sections.

\subsection{Study Area}

Karnataka exhibits considerable variation in the distribution of temperature and rainfall with varying topographic boundaries. It has been divided into ten agro-climatic zones based on variations in climatic factors. The ten agro-climatic zones are viz., North Eastern Transition Zone, North Eastern Dry Zone, Northern Dry Zone, Central Dry Zone, Eastern Dry Zone, Southern Dry Zone, Southern Transition Zone, Northern Transition Zone, Hilly Zone, and Coastal Zone. The map of Karnataka, India showing its agroclimatic zones, is given in Fig. 3 .

Karnataka observes four climatological seasons: winter (January and February), summer (March to May), a monsoon (June to September) and a post-monsoon period (October to December). Karnataka state has good variability in its rainfall pattern. The highest rainfall with an average of 3,638.5 mm (143 in) per annum is noticed in coastal zone of Karnataka. The variability of rainfall is reported to be $800 \mathrm{~mm}$ in the western area to $1600 \mathrm{~mm}$ in the eastern area of Karnataka. Therefore, it is necessary to estimate reference evapotranspiration by considering different agro-climatic conditions for the best irrigation planning and management practices.

\subsection{Climate Data Collection}

The daily climatic data for each station in different agro-climatic zones of Karnataka for a span of 35 years (1979-2014) were collected from the website Global Weather Data for SWAT (https://globalweather.tamu.edu/). The climate data comprises of daily maximum temperature, minimum temperature, mean relative humidity, wind speed, and solar radiation for periods of 35 years. The ten climate stations representing each agro-climatic zones have been considered in the present study. Even though there are many stations located in the agro-climatic zones, stations which have typical values representing the respective agro-climatic conditions are considered in this study. For each of the climate stations, geographic attributes such as longitude, latitude, and elevation were also obtained. The distribution of climate stations under study in the state are shown in Fig. 4. Table 1 presents the salient features of climate stations of 10 agro-climatic zones of Karnataka. 
Table 1

Salient features of climate stations of 10 agro-climatic zones of Karnataka

\begin{tabular}{|lllll|}
\hline Agro-climatic Zone & Climate Station & Longitude & Latitude & Elevation (m) \\
\hline North Eastern Transition Zone & Bidar & $17.9104^{\circ} \mathrm{N}$ & $77.5199^{\circ} \mathrm{E}$ & 710 \\
\hline North Eastern Dry Zone & Kalburgi & $17.3297^{\circ} \mathrm{N}$ & $76.8343^{\circ} \mathrm{E}$ & 454 \\
\hline Northern Dry Zone & Bijapur & $16.8302^{\circ} \mathrm{N}$ & $75.7100^{\circ} \mathrm{E}$ & 592 \\
\hline Central Dry Zone & Chickmagalur & $13.3161^{\circ} \mathrm{N}$ & $75.7720^{\circ} \mathrm{E}$ & 1090 \\
\hline Eastern Dry Zone & Bangalore & $12.9716^{\circ} \mathrm{N}$ & $77.5946^{\circ} \mathrm{E}$ & 920 \\
\hline Southern Dry Zone & Mysore & $12.2958^{\circ} \mathrm{N}$ & $76.6394^{\circ} \mathrm{E}$ & 763 \\
\hline Southern Transition Zone & Hassan & $13.0033^{\circ} \mathrm{N}$ & $76.1004^{\circ} \mathrm{E}$ & 980 \\
\hline Northern Transition Zone & Belgaum & $15.8497^{\circ} \mathrm{N}$ & $74.4977^{\circ} \mathrm{E}$ & 784 \\
\hline Hilly Zone & Madikeri & $12.4244^{\circ} \mathrm{N}$ & $75.7382^{\circ} \mathrm{E}$ & 1150 \\
\hline Coastal Zone & Udupi & $13.3409^{\circ} \mathrm{N}$ & $74.7421^{\circ} \mathrm{E}$ & 27 \\
\hline
\end{tabular}

The daily climate data sets which are tabulated in a CSV file comprises of maximum and minimum temperature $\left({ }^{\circ} \mathrm{C}\right)$, mean relative humidity $(\%)$, wind speed $(\mathrm{m} / \mathrm{sec})$, solar radiation $\left(\mathrm{MJ} / \mathrm{m}^{2} /\right.$ day), and other site data. The quality and integrity of the data set was performed as per the guidelines provided by (Allen 1996). The number of days having complete climatic data for all stations under study, excluding the outliers are found to be 12928 . The daily reference evapotranspiration $\left(E T_{0}\right)$ values from January to December between 1979-2014 were computed for ten climate stations representing various agroclimatic regions of Karnataka using Python implementation. The developed program for $\mathrm{ET}_{0}$ estimation was validated using examples given in FAO-56 document.

\section{Calculation Of Reference Evapotranspiration (Et)}

The reference evapotranspiration values are influenced by the meteorological variables viz., maximum temperature, minimum temperature, wind speed, relative humidity, solar radiation, and sunshine hours of the locations taken for study. The standard FAO P-M method has been used to calculate daily $\mathrm{ET}_{0}$ of different agro-climatic zones of Karnataka. The general form of the P-M equation is given as follows

$$
\mathrm{ET}_{0}=\frac{0.408 \Delta(R n-G)+\frac{900}{T+273} u 2(e s-e a)}{\Delta+\gamma(1+0.34 u 2)}
$$


Where, $\mathrm{ET}_{0}$ is evapotranspiration, $\mathrm{R}_{\mathrm{n}}$ is the net radiation, $\mathrm{G}$ is the soil heat flux, $\left(\mathrm{e}_{\mathrm{s}}-\mathrm{e}_{\mathrm{a}}\right)$ is the vapour pressure deficit of the air, $Y$ is the psychometric constant, $\Delta$ is the slope of the vapour pressure curve, $\lambda$ is the latent heat of vaporization, $T$ is the air temperature at $2 \mathrm{~m}$ height, $\mathrm{u}_{2}$ is the wind speed at $2 \mathrm{~m}$ height, $\mathrm{e}_{\mathrm{s}}$ is saturation vapour pressure in $\mathrm{kPa}, \mathrm{e}_{\mathrm{a}}$ is actual vapour pressure in $\mathrm{kPa}, \mathrm{D}$ is slope vapour pressure curve in $\mathrm{KPa} \circ \mathrm{C}, \mathrm{g}$ is psychometric constant in $\mathrm{kPa} \circ \mathrm{C}$. $\mathrm{ET}_{0}$ can be estimated by means of the FAO P-M method which involves certain calculation procedures given in as Appendix-I in the supplementary file.

\section{Time Series Trend Analysis}

The $\mathrm{ET}_{0}$ values of the agro-climatic zones can be analysed to detect the presence of significant trends and their magnitudes during the study period. The trends of climate variables of the stations which influence the $\mathrm{ET}_{0}$ values can also be investigated. The presence of specific types of trends in the meteorological time series data are best detected by the non-parametric tests. Non-parametric tests are simple and robust in design and are easy to understand. They are distribution free and hence fewer assumptions required for the data, and they can cope up with outliers/missing values in the dataset (Crawford et al. 1983). The most widely accepted non-parametric method as recommended by the World Meteorological Organization (WMO) is the Mann-Kendall test. The Mann-Kendall test (Mann 1945) detects long term trends in the hydro-meteorological time series data (Shadmani et al. 2012; Azizzadeh and Javan 2015). The advantages of this method are: it does not require the data to be normally distributed, and not affected by the missing data, which are quite common in hydro-metrological time series.

\subsection{Mann-Kendall (MK) test}

The Mann-Kendall is a statistical hypothesis test procedure to determine the presence of trends in the given time series data. It does not estimate the magnitude of the trends. The test procedure is given as follows. Let $\left(x_{1}, x_{2}, . . x_{n}\right)$ be a sequence of data samples measured over the time period. As per the test, the null hypothesis $\left(\mathrm{H}_{0}\right)$ is that the data are independent and identically distributed (meaning there is no trend). The alternate hypothesis $\left(\mathrm{H}_{1}\right)$ is that there is a monotonic trend over the time period. The MannKendall test statistic $S$ is

$$
\mathrm{S}=\sum_{k=1}^{n-1} \sum_{j=k+1}^{n} \operatorname{sgn}(\mathrm{xj}-\mathrm{xk})
$$

Where, $x_{i}$ and $x_{j}$ are the values in the dataset $(1<i<j<n) ; n$ is the size of the dataset; sgn () is the sign function which can be computed as 


$$
\operatorname{sgn}(x j-x k)=\left\{\begin{array}{c}
1 \text { if }(x j-x k)>0 \\
0 \text { if }(x j-x k)=0 \\
-1 \text { if }(x j-x k)<0
\end{array}\right.
$$

A positive value of $S$ indicates that there is an increasing trend and a negative value is an indicator of a decreasing trend. $S$ is a normal distribution with mean value of 0 and a variance of

$$
\operatorname{Var}(\mathbf{S})=\left[\frac{n(n-1)(2 n+5)-\sum_{t} t(t-1)(2 t+5)}{18}\right]
$$

Where, $\mathrm{t}$ denotes the tie, and $\sum_{\mathrm{t}}$ indicates the summation over all ties.

The exact distribution of $S$ for $n \leq 10$ was given by (Mann 1945) and (Kendall 1975). So, the significance of the test can be tested by computing the standard statistic test $(Z)$ and is given by

$$
Z= \begin{cases}\frac{S-1}{\sqrt{\operatorname{Var}(S)}}, & \text { if } S>0 \\ 0, & \text { if } S=0 \\ \frac{S+1}{\sqrt{\operatorname{Var}(S)},} & \text { if } S<0\end{cases}
$$

$\operatorname{Var}(\mathrm{S})$ is the variance of statistics $\mathrm{S}$ and $\mathrm{Z}$ is the Mann-Kendall test statistics with standard normal distribution with mean 0 and variance 1 . This $Z$ statistic can be used when the number of samples $n>10$. The trend's significance is assessed by comparing the $Z$ value with the standard normal variation at the pre-specified level of statistical significance (Hamed and Rao 1998). In a two-sided trend test, with a representing the significance level, the null hypothesis should not be accepted if $|Z|>Z_{a / 2}$, suggesting that the trend is significant. A positive $Z$ value at the significance level implies a positive trend, whereas a negative value indicates a negative trend. The significance of a trend can be verified by the $p$-value (probability value) obtained from the $\mathrm{M}-\mathrm{K} Z$ value. If the $\mathrm{p}$-value is less than the predetermined significance level (e.g. $a=5 \%$ ) or greater than the confidence level (if $a=5 \%$, confidence level $=95 \%$ ), the null hypothesis of the trend cannot be accepted.

\subsection{Theil-Sen's estimator}

The Mann-Kendall test doesn't estimate the slope of trends. Sen's slope is the most popular non parametric method to estimate the magnitude of trends in a sample of $n$ pairs of data (Sen 1968). It can handle missing values, insensitive to outliers, and requires no assumptions on probability distribution of data. The major steps in this method are: (i) Calculate the slopes for pairs of data points, (ii) Determine the median of all slopes from step(i). The slope of $n$ pairs of data points was estimated using the following formula: 
$\beta=\operatorname{Median}\left(\frac{x j-x i}{j-i}\right)$ for all $i<j$

Where, $1<j<i<n$ and $b$ is the estimate of the trend magnitude. A positive value of $b$ indicates an upward trend, and negative value of $\mathrm{b}$ indicates a downward trend.

\section{Results And Discussions}

The monthly average reference evapotranspiration, $\mathrm{ET}_{0}$ of ten stations representing the agro-climatic zones of Karnataka were calculated from 1979 through 2014 was observed to have the higher values in the month of March for stations like Bangalore, Chikmagalur, Hassan, and Madikeri. The daily $\mathrm{ET}_{0}$ values were estimated to be above $6.0 \mathrm{~mm} /$ day for all these four stations mentioned above. However, for climate stations like Belgaum, Bijapur, Mysore and Udupi, the monthly average $\mathrm{ET}_{0}$ values were found to be higher in the month of April, ranging from $4.06 \mathrm{~mm} /$ day to $7.22 \mathrm{~mm} /$ day. Whereas, in stations like Bidar and Kalburgi the monthly average $\mathrm{ET}_{0}$ values were found to be higher in the month of May and the daily $\mathrm{ET}_{0}$ values were found to be $7.0 \mathrm{~mm} /$ day and above. These higher $\mathrm{ET}_{0}$ values for the above the mentioned climatic stations fall during the summer months characterized by higher in temperatures, lower relative humidity values, higher wind speeds and longer sunshine hours. The minimum daily $\mathrm{ET}_{0}$ values ranged between $1.59 \mathrm{~mm} /$ day to $4.0 \mathrm{~mm} /$ day between the months of July and August for all ten climatic stations which may be due to change in the season from summer to monsoon or winter characterized by decrease in temperature, wind speed and sun shine hours and higher values of relative humidity.

The study carried out by ( Labedzki et al. 2011) reported the estimation of $\mathrm{ET}_{0}$ values using FAO P-M method for 40 climate stations in Poland for the duration 1979-2004. The daily mean $\mathrm{ET}_{0}$ values for all the 40 climate stations were observed to be in the range of 2 to $4 \mathrm{~mm} /$ day. Further, the lowest average monthly sums of $\mathrm{ET}_{0}$ values in southern Poland regions indicate the steady meteorological conditions unlike the (climate conditions of the) results obtained by the current research work. Similar kind of investigation carried out by ( $\mathrm{Li}$ et al. 2012) who used FAO P-M method for the calculation of $\mathrm{ET}_{0}$ values for the Loess Plateau of China during 1961-2009. The average annual $\mathrm{ET}_{0}$ value was found to be 1060.3 $\mathrm{mm}$ with the lowest $\mathrm{ET}_{0}$ values observed in south-west region and the highest $\mathrm{ET}_{0}$ values in the northwest region. This variation of $\mathrm{ET}_{0}$ values were due to the climatic factors such as low temperature, wind speed, high relative humidity and short duration of sun-shine hours in the south-west region. The highest $\mathrm{ET}_{0}$ values in north-west region were mainly caused by the low values of relative humidity, high wind speed and longer sun-shine hours. These observations signify the influence of climate variables on $\mathrm{ET}_{0}$ values as presented in the above findings. The average $\mathrm{ET}_{0}$ obtained by FAO P-M method for the climatic data of Yaoundé for the duration of 15 years (1967-1982) was found to be $3.16 \mathrm{~mm} /$ day (Tellen 2017). The lowest $\mathrm{ET}_{0}$ value of $2.59 \mathrm{~mm} /$ day in the coldest month of August, and the highest $\mathrm{ET}_{0}$ value of 3.63 
$\mathrm{mm} /$ day in the hottest month of February with no major variations in wind speed throughout the year were observed.

(Poddar et al. 2018) assessed the daily $\mathrm{ET}_{0}$ values of sub-humid sub-tropical agro-climatic locations of western Himalayas (Himachal Pradesh, India) for the duration of 5 years (2011-2016) using the FAO P-M method. The mean value of daily $\mathrm{ET}_{0}$ averaged over all 6 stations was $3.75 \mathrm{~mm} /$ day. It was found that the variations in values of solar radiation, temperature and relative humidity have an implicit effect on $\mathrm{ET}_{0}$ values of the regions under study. (Jhajharia et al. 2015) estimated the annual and seasonal $\mathrm{ET}_{0}$ values through the FAO P-M method for the meteorological data of Bikaner located in the Thar Desert (Rajasthan) in India, for the duration of 39 years (1967-2005). The highest (2242.4 mm) and the lowest $\left(1520.42 \mathrm{~mm}\right.$ ) annual $\mathrm{ET}_{0}$ values were mainly due to the highest and the lowest annual wind speed values respectively at the study region. The annual mean $\mathrm{ET}_{0}$ value was found to be $1863.82 \mathrm{~mm}$ with the coefficient of variation $9.77 \%$. At the seasonal time scale, the highest mean $\mathrm{ET}_{0}$ value was observed during pre-monsoon, followed by monsoon and post-monsoon. The lowest mean $\mathrm{ET}_{0}$ value was reported during winter season. The coefficient of variation value ranged between $10.5 \%-13 \%$ for the different seasons. These seasonal variations are again due to the fluctuations in the wind speed during the summer and winter seasons.

The temporal and statistical variability of $\mathrm{ET}_{0}$ values across the various agro-climatic zones were done by the various statistical measures. The mean, minimum, maximum, standard deviation, coefficient of variation, and median values characterize the spatial and temporal distributed $\mathrm{ET}_{0}$ values.

\subsection{Temporal variability of $\mathrm{ET}_{0}$}

The monthly average of $\mathrm{ET}_{0}$ across ten climate stations under the agro-climatic zones of Karnataka characterizes the multi-year mean reference evapotranspiration that ranged between $85.49 \mathrm{~mm}$ in August to $189.38 \mathrm{~mm}$ in April as shown in Table 2. This implies that the mean daily $\mathrm{ET}_{0}$ ranges from $2.8 \mathrm{~mm} /$ day to $6.31 \mathrm{~mm} /$ day. The coefficient of variation (CV) ranges from $9-37 \%$ for monthly sums in multi-year period in case of temporal variability analysis. Similar kind of investigation involving estimation of $\mathrm{ET}_{0}$ using FAO P-M method and spatial and temporal analysis have been done by (Yadav et al. 2017) using the daily climate data of 34 years (1979-2004) for five agro-climatic zones of Madhya Pradesh, India. The daily mean $\mathrm{ET}_{0}$ varied from $4 \mathrm{~mm}-10 \mathrm{~mm} /$ day which is higher than that of the $\mathrm{ET}_{0}$ values obtained for the current study. However, the coefficient of variation was reported to be between $6-20 \%$. This lower range of values of $\mathrm{ET}_{0}$ are due to the existence of wide range of climatic conditions such as moist subhumid to dry sub-humid, semi-arid to dry sub-humid and semi-arid in various zones of Madhya Pradesh for the duration taken for study. The highest $\mathrm{ET}_{0}$ values were observed in the regions that receive less rainfall. ( $Ł a b e d z k i$ et al. 2011) also estimated $\mathrm{ET}_{0}$ values using FAO P-M method and carried spatial and temporal analysis considering 10-day average weather data for a period of 34 years (1970-2004) for 40 climate stations of Poland. The daily mean $\mathrm{ET}_{0}$ values were found to be between 2 to $4 \mathrm{~mm} / \mathrm{day}$ and compared to be lower than the values obtained in the current research. This attributes to the climatic 
conditions prevailing in Poland, which is located closer to the northern hemisphere characterized by cold and dry weather during most of the period in a year. Thus the coefficient of variation falls within the range of 2 to $15 \%$, which is quite narrow compared to the temporal variations of the regions under study. The $\mathrm{ET}_{0}$ values of 22 meteorological stations of Himachal Pradesh, India was quantified using FAO P-M method for the duration of 29 years (1980-2009) by (Garg et al. 2016). The mean daily $\mathrm{ET}_{0}$ varied from 6 $\mathrm{mm} /$ day to $9 \mathrm{~mm} /$ day, which is quite higher compared to the results of the present study. The major cause for this is the significant variation in temperature and precipitation patterns across the state. The coefficient of variation of $\mathrm{ET}_{0}$ values was found to be in the range 17 to $20 \%$ for monthly sums averaged over 22 stations.

Table 2 Statistics of temporal variability of $\mathrm{ET}_{0}$ values averaged over 10 stations between 1979 to 2014

\begin{tabular}{|l|c|c|c|c|c|c|c|c|c|c|c|c|}
\hline & January & Febrary & March & April & May & June & July & \multicolumn{2}{|c|}{ August } & September & October November December \\
\hline Kalburgi & 137.356 & 173.358 & 208.423 & 225.13 & 222.214 & 155.99 & 126.7 & 121.56 & 140.01 & 145.4 & 135.289 & 131.932 \\
\hline Bidar & 130.901 & 165.232 & 198.923 & 214.08 & 215.798 & 153.95 & 120.6 & 110.05 & 131.399 & 139.105 & 130.57 & 127.287 \\
\hline Bijapur & 136.286 & 171.517 & 203.756 & 216.65 & 209.223 & 145.18 & 110.2 & 106.32 & 128.118 & 137.201 & 131.185 & 129.365 \\
\hline Chickmagal & 146.397 & 174.224 & 186.423 & 172.22 & 156.774 & 71.195 & 49.19 & 50.428 & 92.899 & 111.81 & 119.33 & 128.905 \\
\hline Bangalore & 136.664 & 166.363 & 187.974 & 182.45 & 170.151 & 126.27 & 100.6 & 97.214 & 121.712 & 117.78 & 113.138 & 118.041 \\
\hline Mysore & 147.264 & 181.565 & 208.623 & 213.01 & 201.66 & 146.58 & 126.5 & 126.61 & 145.67 & 138.872 & 126.583 & 128.189 \\
\hline Hassan & 139.522 & 167.781 & 182.707 & 169.33 & 155.705 & 80.603 & 58.81 & 60.054 & 99.451 & 109.908 & 113.1 & 121.057 \\
\hline Belgaum & 145.345 & 167.781 & 203.388 & 205.76 & 187.454 & 91.607 & 51.86 & 51.886 & 95.567 & 121.029 & 125.932 & 132.344 \\
\hline Madikeri & 157.273 & 167.781 & 187.388 & 173.42 & 157.924 & 71.971 & 54.65 & 60.478 & 102.75 & 117.42 & 129.628 & 141.752 \\
\hline Udupi & 99.634 & 167.781 & 118.932 & 121.78 & 114.238 & 81.782 & 72.71 & 70.325 & 81.211 & 88.432 & 96.874 & 99.46 \\
\hline Mean & 137.66 & 166.67 & 188.65 & 189.38 & 179.11 & 112.51 & 87.17 & 85.49 & 113.87 & 122.69 & 122.16 & 125.83 \\
\hline Median & 138.43 & 172.43 & 193.45 & 194.1 & 178.8 & 108.94 & 86.65 & 83.76 & 112.23 & 119.4 & 126.25 & 128.54 \\
\hline Std & 15.31 & 20.54 & 26.33 & 31.67 & 34.11 & 36.17 & 32.82 & 29.86 & 22.2 & 17.53 & 11.66 & 11.26 \\
\hline CV & 11.12 & 12.32 & 13.96 & 16.72 & 19.04 & 32.14 & 37.65 & 34.93 & 19.5 & 14.29 & 9.55 & 8.95 \\
\hline Min & 99.633 & 110.297 & 118.932 & 121.78 & 114.238 & 71.195 & 49.19 & 50.428 & 81.211 & 88.432 & 96.874 & 99.46 \\
\hline Max & 157.273 & 181.565 & 208.623 & 225.13 & 222.214 & 155.99 & 126.7 & 126.61 & 145.67 & 145.4 & 135.289 & 141.752 \\
\hline
\end{tabular}

\subsection{Spatial variability of $\mathrm{ET}_{0}$}

The monthly average reference evapotranspiration $\mathrm{ET}_{0}$, over 35 years characterise the spatial variability of multi-year mean reference evapotranspiration. The lowest monthly sums of $\mathrm{ET}_{0}$ found in Chikmagalur station in July $(49.19 \mathrm{~mm})$ and highest in Kalburgi in April $(225.12 \mathrm{~mm})$. The coefficient of variation ranges from $18-40 \%$, which is higher than that of temporal variability. Hence the spatial variability of $\mathrm{ET}_{0}$ is higher than the temporal variability indicating there is a higher variation of $\mathrm{ET}_{0}$ in the space than in the years. The results obtained by (Yadav et al. 2017) from Madhya Pradesh, India reveal that the lowest monthly sums of $E T_{0}$ is $76 \mathrm{~mm}$ and the highest value is $331 \mathrm{~mm}$. The coefficient of variation ranged from 3-20\%, which is lower than temporal variability (except in August) indicating the differentiation of $\mathrm{ET}_{0}$ 
values is more in the years than in the regions. The spatial variability was higher than the temporal variability with coefficient of variation ranging from $30-57 \%$ indicating the substantial variation of $\mathrm{ET}_{0}$ values in the stations than in the study period (Garg et al. 2016). Further, the maximum $\mathrm{ET}_{0}$ was noted in the south-west part of the state which exhibit uncertain meteorological conditions. The northern part of the state characterized by dry and cold regions with minimum rainfall witnessed the lowest values of $\mathrm{ET}_{0}$. ( tabedzki et al. 2014) from Poland reported that the average monthly sums of $\mathrm{ET}_{0}$ ranged between 469 $\mathrm{mm}-566 \mathrm{~mm}$. The coefficient of variation ranged from $5-7 \%$, which is lower than temporal variability of $\mathrm{ET}_{0}$ values indicating that there is a significant variation of $\mathrm{ET}_{0}$ values in the years than in the regions under study.

The average monthly reference evapotranspiration in different climate stations is as depicted in the following figure.

\subsection{Trend analysis of Reference Evapotranspiration $\left(\mathrm{ET}_{0}\right)$}

The annual of P-M ET 0 values for 10 stations of agro-climatic zones of Karnataka between 1979-2014 were analysed using the Mann-Kendall test and Theil Sen's slope estimator methods. Both the tests were implemented using Python version 3.9.1 in the PyCharm editor, which offers sophisticated functionalities for time series analysis. Trends of both $\mathrm{ET}_{0}$ and climate variables were determined statistically at $1 \%$ significant level. The outcomes of the test include the normalized test statistic Z, Kendall's Tau statistic which measure the significance of the test, and a 2-sided p-value for testing the hypothesis as presented in Table 3. The positive value of Tau indicates an upward trend and a negative value indicates a downward trend. From the table it can be noted that all the 10 stations showed an increasing trend in annual $\mathrm{ET}_{0}$ values during the study period.

The results of the Mann-Kendall test and Sen's slope estimator for the annual $\mathrm{ET}_{0}$ time series and the corresponding meteorological variables for all 10 stations under study are given in Table 3 . 
Table 3

Mann-Kendall test and Sen's slope estimator results of $\mathrm{ET}_{0}$ and climate variables on annual scale

\begin{tabular}{|c|c|c|c|c|c|c|}
\hline Climate Station & Variables & p-value & Z-value & Tau & Trend & Slope \\
\hline \multirow[t]{5}{*}{ Bidar } & $\mathrm{ET}_{0}$ & 0.191 & 1.307 & 0.156 & Increasing & 1.376 \\
\hline & Temperature & 0.334 & 0.966 & 0.116 & Increasing & 3.027 \\
\hline & Relative Humidity & 0.426 & 0.795 & 0.096 & Increasing & 0.159 \\
\hline & Wind Speed & 0.053 & -1.931 & -0.230 & Decreasing & -1.052 \\
\hline & Solar Radiation & 0.065 & 1.846 & 0.220 & Increasing & 6.784 \\
\hline \multirow[t]{5}{*}{ Kalburgi } & $\mathrm{ET}_{0}$ & 0.010 & 2.585 & 0.308 & Increasing & 2.541 \\
\hline & Temperature & 0.017 & 2.386 & 0.284 & Increasing & 5.764 \\
\hline & Relative Humidity & 0.932 & -0.085 & -0.012 & Decreasing & -0.013 \\
\hline & Wind Speed & 0.021 & -2.301 & -0.274 & Decreasing & -1.202 \\
\hline & Solar Radiation & 0.006 & 2.755 & 0.328 & Increasing & 8.026 \\
\hline \multirow[t]{5}{*}{ Bijapur } & $\mathrm{ET}_{0}$ & 0.004 & 2.897 & 0.345 & Increasing & 2.837 \\
\hline & Temperature & 0.006 & 2.727 & 0.324 & Increasing & 8.183 \\
\hline & Relative Humidity & 0.3342 & -0.966 & -0.116 & Decreasing & -0.165 \\
\hline & Wind Speed & 0.712 & 0.369 & 0.046 & Increasing & 0.344 \\
\hline & Solar Radiation & 0.008 & 2.642 & 0.314 & Increasing & 10.693 \\
\hline \multirow[t]{5}{*}{ Chikmagalur } & $\mathrm{ET}_{0}$ & 0.094 & 1.675 & 0.2 & Increasing & 1.641 \\
\hline & Temperature & 0.012 & 2.527 & 0.301 & Increasing & 9.620 \\
\hline & Relative Humidity & 0.532 & 0.625 & 0.0756 & Increasing & 0.094 \\
\hline & Wind Speed & 0.514 & -0.653 & -0.079 & Decreasing & -0.572 \\
\hline & Solar Radiation & 0.050 & 1.960 & 0.234 & Increasing & 9.947 \\
\hline \multirow[t]{5}{*}{ Bangalore } & $\mathrm{ET}_{0}$ & 0.000 & 3.323 & 0.395 & Increasing & 4.168 \\
\hline & Temperature & 4.874 & 4.062 & 0.482 & Increasing & 11.915 \\
\hline & Relative Humidity & 0.910 & -0.114 & -0.015 & Decreasing & -0.016 \\
\hline & Wind Speed & 0.977 & 0.028 & 0.0050 & Increasing & 0.093 \\
\hline & Solar Radiation & 0.000 & 3.550 & 0.422 & Increasing & 19.678 \\
\hline Mysore & $\mathrm{ET}_{0}$ & 0.025 & 2.244 & 0.267 & Increasing & 2.566 \\
\hline
\end{tabular}




\begin{tabular}{|c|c|c|c|c|c|c|}
\hline Climate Station & Variables & $\mathrm{p}$-value & Z-value & Tau & Trend & Slope \\
\hline & Temperature & 0.021 & 2.301 & 0.274 & Increasing & 7.891 \\
\hline & Relative Humidity & 0.842 & -0.199 & -0.025 & Decreasing & -0.031 \\
\hline & Wind Speed & 0.888 & 0.142 & 0.018 & Increasing & 0.128 \\
\hline & Solar Radiation & 0.047 & 1.988 & 0.237 & Increasing & 10.095 \\
\hline \multirow[t]{5}{*}{ Hassan } & $\mathrm{ET}_{0}$ & 0.000 & 3.867 & 0.459 & Increasing & 3.693 \\
\hline & Temperature & 0.000 & 3.863 & 0.459 & Increasing & 9.701 \\
\hline & Relative Humidity & 0.932 & 0.085 & 0.012 & Increasing & 0.008 \\
\hline & Wind Speed & 0.820 & -0.227 & -0.029 & Decreasing & -0.166 \\
\hline & Solar Radiation & 0.000 & 3.834 & 0.455 & Increasing & 20.693 \\
\hline \multirow[t]{5}{*}{ Belgaum } & $\mathrm{ET}_{0}$ & 0.065 & 1.846 & 0.220 & Increasing & 1.364 \\
\hline & Temperature & 0.008 & 2.670 & 0.318 & Increasing & 9.356 \\
\hline & Relative Humidity & 0.334 & 0.966 & 0.116 & Increasing & 0.151 \\
\hline & Wind Speed & 0.443 & -0.767 & -0.092 & Decreasing & -0.332 \\
\hline & Solar Radiation & 0.256 & 1.136 & 0.136 & Increasing & 4.831 \\
\hline \multirow[t]{5}{*}{ Madikeri } & $\mathrm{ET}_{0}$ & 0.001 & 3.1243 & 0.371 & Increasing & 2.909 \\
\hline & Temperature & 7.729 & 4.942 & 0.587 & Increasing & 13.461 \\
\hline & Relative Humidity & 0.820 & -0.228 & -0.028 & Decreasing & -0.0304 \\
\hline & Wind Speed & 0.478 & -0.710 & -0.086 & Decreasing & -0.430 \\
\hline & Solar Radiation & 0.001 & 3.266 & 0.388 & Increasing & 16.004 \\
\hline \multirow[t]{5}{*}{ Udupi } & $\mathrm{ET}_{0}$ & 0.201 & 1.278 & 0.153 & Increasing & 1.095 \\
\hline & Temperature & 0.000 & 3.749 & 0.445 & Increasing & 6.439 \\
\hline & Relative Humidity & 0.017 & 2.386 & 0.284 & Increasing & 0.125 \\
\hline & Wind Speed & 0.041 & -2.045 & -0.244 & Decreasing & -2.970 \\
\hline & Solar Radiation & 0.000 & 3.437 & 0.408 & Increasing & 13.281 \\
\hline
\end{tabular}

From the Table 3, it can be seen that a significant positive trend in annual mean $\mathrm{ET}_{0}$ was observed in Bangalore station though there was a considerable decrease in annual $\mathrm{ET}_{0}$ values in the middle of the entire study period. The increased values of mean temperature, solar radiation, wind speed and decreased 
vales of relative humidity would have contributed to the positive annual $\mathrm{ET}_{0}$ trend. These results are found to be in agreement with the significant positive $\mathrm{ET}_{0}$ trend observed in Southern Spain for the duration 1960-2005 (Espadafor et al. 2011). The average annual $\mathrm{ET}_{0}$ value ranged between $1271 \mathrm{~mm}$ to $1661 \mathrm{~mm}$ for Bangalore station.

An overall positive trend in annual mean $\mathrm{ET}_{0}$ was observed in Belgaum station, mainly due to the influence of increasing mean air temperature and solar radiation. However, the lowest value of annual $\mathrm{ET}_{0}$ of $1291 \mathrm{~mm}$ was observed in the year 1990 which is still at higher side compared to the average lowest value of $\mathrm{ET}_{0}$ reported at Udupi station in the 35 years of study period.

The annual $\mathrm{ET}_{0}$ values of Bijapur station revealed an upward trend which is mainly because of the fall in relative humidity and rise in mean temperature, solar radiation and wind speed values. The lowest and the highest average annual $\mathrm{ET}_{0}$ values observed were $1463 \mathrm{~mm}$ and 1777 respectively. However, the Chikmagalur station, located in central dry zone, also experiences hot and dry summers, indicates an upward trend in annual $\mathrm{ET}_{0}$ values even though with decreasing trend in wind speed values. The annual $\mathrm{ET}_{0}$ value ranged from $1186 \mathrm{~mm}$ to $1392 \mathrm{~mm}$. Similar results were reported by (Bandyopadhyay et al. 2009) for the arid climatic conditions of Deccan Plateau in India which exhibited a positive annual $\mathrm{ET}_{0}$ trend.

From Table 3, a positive trend in $\mathrm{ET}_{0}$ values of Hassan station is observed with the average annual $\mathrm{ET}_{0}$ values varying between $1149 \mathrm{~mm}$ to $1460 \mathrm{~mm}$. Even though the decrease in the wind speed over the 35 year of study period was observed, the increase in climatic variables like, mean temperature and solar radiation, decreased values of relative humidity have predominantly contributed to the increasing trend in $\mathrm{ET}_{0}$ values. These results are found to be in agreement with $\mathrm{ET}_{0}$ trends of the yellow river basin in China (Liu 2004), western coast of Madagascar (Djaman et al. 2018), and northwest regions of Iran (Tabari 2011). The Kalburgi station situated in north eastern arid zone is mostly hot year around (annual temperature range: $18^{\circ} \mathrm{C}-40^{\circ} \mathrm{C}$ ), with dry climate in summer and winter. The station witnessed the minimum annual mean $\mathrm{ET}_{0}$ value of $1522 \mathrm{~mm}$ and the maximum value of $1841 \mathrm{~mm}$, which is the highest annual mean $\mathrm{ET}_{0}$ value observed amid of all the 10 stations as presented in the Fig. 6. A positive trend in average annual $\mathrm{ET}_{0}$ was observed during the study period majorly due to the simultaneous occurrence of rising mean air temperature, solar radiation, and decrease in relative humidity values.

The hilly weather station Madikeri with tropical highland climate observes fairly moderate weather with constant temperature throughout the year. The positive annual trends of $\mathrm{ET}_{0}$ were contributed by the increasing temperature and solar radiation values and decrease in relative humidity for the study duration. The mean annual $\mathrm{ET}_{0}$ ranged between $1248 \mathrm{~mm}$ to $1473 \mathrm{~mm}$.

It can be seen that from Table 3, Bidar station, which is in semi-arid climate zone indicated a significant upward trend in average annual $\mathrm{ET}_{0}$ values. It is attributed to the increasing trends in mean temperature, solar radiation, relative humidity values, and decreased trend in wind speed during the study period. The 
annual $\mathrm{ET}_{0}$ value ranged from $1436 \mathrm{~mm}$ to $1754 \mathrm{~mm}$. Similar results were reported in the north eastern part of Iran (Azzizadeh and Javan 2015).

Mysore station characterized by the dry climate in southern Karnataka reveals an upward trend in the mean annual $\mathrm{ET}_{0}$ values for the 35 years of study period. The annual $\mathrm{ET}_{0}$ varied from $1517 \mathrm{~mm}$ to 1823 $\mathrm{mm}$. The increase in meteorological variables like mean temperature, wind speed and solar radiation, decreased values of relative humidity have shown a significant influence on the positive $\mathrm{ET}_{0}$ trend. These outcomes are found to be in agreement with the annual $\mathrm{ET}_{0}$ trends in dry regions of Rajasthan, Gujarat, and western Madhya Pradesh of India (Goroshi et al. 2017).

From Table 3, Udupi station, characterized by the tropical monsoon climate, located in the coastal zone of the state observed an upward trend in average annual $\mathrm{ET}_{0}$ during the period taken for study. The minimum mean annual $\mathrm{ET}_{0}$ recorded was $943 \mathrm{~mm}$, which is the lowest of the mean annual $\mathrm{ET}_{0}$ among the 10 stations. The maximum mean annual $\mathrm{ET}_{0}$ was $1106 \mathrm{~mm}$. Even though there was a feeble increase in the relative humidity and decrease in wind speed, the increased solar radiation and mean temperature would have majorly contributed towards the increasing trend in the $\mathrm{ET}_{0}$ values. The annual $\mathrm{ET}_{0}$ variation for the station is plotted in Fig. 7.

The solid line in the Sen's slope plot indicates the least squares fit for the comparison (regression line) and the regular square dots show the various data points. Figure 8 shows a positive trend in annual $\mathrm{ET}_{0}$ values for Kalburgi station, calculated using Sen's slope method. An increasing annual $\mathrm{ET}_{0}$ trend was observed at Udupi station as depicted in Fig. 9.

\subsection{Trend analysis of climate variables}

The major climatic variables affecting the evapotranspiration process are air temperature, wind speed, relative humidity, solar radiation. Hence, it is necessary to investigate the impact of these climate variables on the annual $\mathrm{ET}_{0}$ values of the stations under study. The annual trends in climatic parameters for the study period in 10 stations are investigated by Mann-Kendall test. The corresponding magnitudes of the slopes detected by Sen's estimator are presented in Table 3.

\subsubsection{Trend of Mean Air Temperature}

The increase in air temperature increases the water vapour in the atmosphere which in turn results in higher rate of evapotranspiration. As per the M-K test results, all the 10 stations showed a significant upward trend in mean annual air temperature during the study period. The heat radiated from the earth, exothermic chemical reactions, increased concentrations of greenhouse gases generated by various human activities, increased urbanization may be the sources for the incessant increase in mean air temperature of the stations under study (Soltani and Soltani 2008; Duhan et al. 2013; Tabari and Talaee 2011). The mean temperature showed an increasing trend in Bidar with the lowest and highest annual temperatures of $8775^{\circ} \mathrm{Cand} 9933^{\circ} \mathrm{C}$ respectively as presented in the Fig. 10. The increasing values of mean temperature influence the annual $\mathrm{ET}_{0}$ values in Bidar station to a larger extent during the study 
period. A positive trend in mean temperature was observed as reported by (Pandey and Pandey, 2013) for the 3 stations of Tons River Basin in India. (Tabari et al. 2011) reported that the 20 climate stations in western half of Iran identified an increasing annual temperature trend which was the primary cause for the positive trend in $\mathrm{ET}_{0}$ values. The increasing $\mathrm{ET}_{0}$ trend was mainly due to the increasing mean temperature in Yellow River Basin as observed by (Wang et al. 2012a, b).

\subsubsection{Trend of Relative humidity}

Relative humidity is the ratio between the amount of moisture in the air and the highest probable level of moisture present in the air at a specific temperature. As the relative humidity of the air increases the evapotranspiration rate decreases. The trend test on climate variables revealed that annual relative humidity has an equivalent number of increasing and decreasing trends among the 10 stations. The increase/decrease in relative humidity in the meteorological stations is attributed towards the temperature drop/rise for a constant amount of water vapour in the atmosphere. A consistent decreasing trend in annual relative humidity was observed which caused a substantial upward trend in annual $\mathrm{ET}_{0}$ values for Kalburgi station during the time taken for study (Fig. 11). Similar results were reported in The Three Gorges Reservoir project of China during the study period (Ma et al. 2018). The diminishing values

of relative humidity had the major impact on increasing trend of annual $\mathrm{ET}_{0}$ in the Tibetan Plateau for the duration 1961-2017, and in the climate stations of western Iran (Liu et al. 2020; Tabari et al. 2011).

\subsubsection{Trend of Wind Speed}

As the wind speed increases, the rate of evapotranspiration also increases. The trend test results showed that about $70 \%$ of the stations exhibited a declining trend in wind speed on an annual scale. This may be attributed to the influence of urban development which has an impact on vegetation growth, environmental factors (Xu et al. 2006; Zhang et al. 2009), impacts of human-specific land usages (Bandyopadhayay et al. 2009; Lopes et al. 2011; McVicar and Roderick 2010). A significant decreasing trend in wind speed was observed in Chikmagalur station for the period 1979-2014 as shown in Fig. 12. The wind speed does not seem to have a major influence on annual $\mathrm{ET}_{0}$ values of the meteorological stations in the present study, which contradicts the results reported by (Gao et al. 2015) wherein wind speed was the key factor towards the variations of $\mathrm{ET}_{0}$ values in the study conducted at 15 climate stations in The West Liao River for the duration of 51 years. (Liu et al. 2017) found out that wind speed did not have significant effect on the $\mathrm{ET}_{0}$ values at the stations of Yellow River catchment which supports the results obtained by the current work. A past research (Zeng et al. 2019) found that wind speed decreased for most of the 79 stations of south west China on the entire study duration and had very minor contribution to the variations of annual $\mathrm{ET}_{0}$ values, which again is in accordance with the outcomes of the existing work.

\subsubsection{Trend of Solar Radiation}

Solar radiation is the main energy source for converting liquid water into water vapour, thus increasing the air temperature. The evapotranspiration increases with the increase in solar radiation. The M-K test revealed that all the 10 stations showed an increasing trend in annual solar radiation during the 35 years 
of study period and can be considered as the dominating factor in view of positive annual $\mathrm{ET}_{0}$ trend. The increased solar radiation at the ten stations may be due to the atmospheric variations such as cloud cover, water vapour, and day length at a specific latitude. However, an upward trend of solar radiation does not always imply the decreasing trend of relative humidity, and vice versa, as observed in the present study. A major increasing trend in annual solar radiation was observed in Bangalore station for the study period as depicted in Fig. 13. The inclining trends of $\mathrm{ET}_{0}$ was explained by the significantly increasing trend of sunshine hours in growing season of 18 stations in Poland ( $Ł a b e ̨ d z k i$ et al. 2014). The results obtained by (Ndiaye et al. 2020) showed that the increased solar radiation had a positive influence on annual $\mathrm{ET}_{0}$ values. The sunshine duration (solar radiation) was the key climate variable in governing the trend of annual $\mathrm{ET}_{0}$ of the 19 stations in the Guizhou Province of south west China during 19592011 (Gao et al. 2016). On the contrary, the mid Himalayan region located in Sikkim state in India observed a downward trend in sunshine duration and hence leading to falling trend of $\mathrm{ET}_{0}$ during Spring (March to May) and monsoon (June to November) season for the study period 1985-2009 (Yadav et al. 2016). The major contributors for the reduction of net solar radiation, and the consequent reduction in $\mathrm{ET}_{0}$ may be the various factors such as, increased amount of aerosols present in the atmosphere, greenhouse gases and the cloud coverage.

\section{Conclusions}

The agro-climatic zones of Karnataka state that are characterized by a wide number of arid and semi-arid regions depends majorly on south west monsoon for crop raise. The irrigation water requirements for agriculture are estimated through precise values of $\mathrm{ET}_{0}$ which is crucial. The Python implementation for the estimation of daily and monthly $\mathrm{ET}_{0}$ values for ten stations under agro-climatic zones using $\mathrm{FAO}$ Penman-Monteith method was found to be in good agreement with examples given FAO - 56 document. The temporal and spatial variability of ETO values reveal that the spatial ones were higher than the temporal values, indicating major differentiation happens with respect to the stations rather than period under study.

The Mann-Kendall trend test carried out for annual $\mathrm{ET}_{0}$ values with $1 \%$ significance level revealed an increasing trend for all the 10 agro-climatic stations for given study period. The trend test conducted on the climate variables such as mean air temperature, wind speed, relative humidity and solar radiation found to have substantial influence on the annual $\mathrm{ET}_{0}$ values. The magnitude variation in the trends estimated by the Theil Sen's slope estimator method revealed that the major upward trend in $\mathrm{ET}_{0}$ may be attributed to the increasing trends of mean air temperature and solar radiation in almost all the climate stations under study. However, wind speed and relative humidity exhibited an equivalent amount of increasing and decreasing trends for these stations. It can be concluded that the potential combination of increasing values of mean air temperature, solar radiation and lower values of relative humidity were the major contributors towards the upward annual $\mathrm{ET}_{0}$ trends in the stations. The influence of wind speed on the annual trend showed marginal impact on the $\mathrm{ET}_{0}$ trends. The highest annual $\mathrm{ET}_{0}$ for the increasing trends was observed to be $1841 \mathrm{~mm}$ for Kalburgi and the lowest value was $943 \mathrm{~mm}$ for Udupi station 
having positive $\mathrm{ET}_{0}$ trend. Thus the results obtained from the above assessment of $\mathrm{ET}_{0}$ values for the agro-climatic zones for three and half decades would be important for predicting the irrigation patterns with the available water resources in future. It might also enable the appropriate crop adaptation practices to increase the viable agricultural production.

\section{Declarations}

Ethics approval and consent to participate - Not Applicable.

Consent for publication - All the authors approved the final manuscript and agreed to its submission to the Environmental Science and Pollution Research.

Availability of data and materials - All data generated or analysed during this study are included in this published article.

Competing interests - The authors declare that they have no known competing financial interests.

Funding - No funds, grants, or other support was received.

Acknowledgements - Not Applicable.

Authors Contributions -

Conceptualization: Jayashree T R

Data Collection and formal analysis: Jayashree T R

Methodology: Jayashree T R

Programming and Validation: Jayashree T R

Visualization: Jayashree T R

Supervision: Subba Reddy N V

Writing - Original Draft: Jayashree T R

Writing - review and editing: Dinesh Acharya $U$

All authors read and approved the final manuscript.

\section{References}

Allen, R. G. (1996). Assessing integrity of weather data for reference evapotranspiration estimation. Journal of irrigation and drainage engineering, 122(2), 97-106. 
Allen, R. G., Pereira, L. S., Raes, D., and Smith, M. 1998. “Crop evapotranspiration: Guidelines for computing crop water requirements." Irrigation and Drainage Paper No. 56, Food and Agricultural Organization of the United Nations, Rome.

Azizzadeh, M., \& Javan, K. (2015). Analyzing trends in reference evapotranspiration in northwest part of Iran. Journal of Ecological Engineering, 16(2).

Bandyopadhayay A, Bhadra A, Raghuwanshi NS, Singh R (2009) Temporal trends in estimates of reference evapotranspiration over India. J Hydrol Eng 14(5):508-518

Crawford, C. G., Hmh. R. M., and Slack, J. R. (1983). Nonparametric tests for trends in water quality data using the statistical analysis system (SAS). Technical Report U. S. Geological Survey Open-File Repon 83550, U. S. Government.

Djaman, K., Ndiaye, P. M., Koudahe, K., Bodian, A., Diop, L., O’Neill, M., \& Irmak, S. (2018). Spatial and temporal trend in monthly and annual reference evapotranspiration in Madagascar for the 1980-2010 period. Int. J. Hydrol, 2, 110-120.

Duhan, D., Pandey, A., Gahalaut, K. P. S., \& Pandey, R. P. (2013). Spatial and temporal variability in maximum, minimum and mean air temperatures at Madhya Pradesh in central India. Comptes Rendus Geoscience, 345(1), 3-21.

Espadafor, M., Lorite, I. J., Gavilán, P., \& Berengena, J. (2011). An analysis of the tendency of reference evapotranspiration estimates and other climate variables during the last 45 years in Southern Spain. Agricultural Water Management, 98(6), 1045-1061.

Gao ZD, He JS, Dong KB, Bian XD, Li X (2015) Sensitivity study of reference crop evapotranspiration during growing season in the West Liao River basin. Theor Appl Climatol, China. doi:10. 1007/s00704015-1453-7

Gao, X., Peng, S., Wang, W., Xu, J., \& Yang, S. (2016). Spatial and temporal distribution characteristics of reference evapotranspiration trends in Karst area: a case study in Guizhou Province, China. Meteorology and Atmospheric Physics, 128(5), 677-688.

Garg, T., Kumar, N., Chauhan, T., \& Kango, R. (2016, September). Estimation of Reference Evapotranspiration using the FAO Penman-Monteith Method for Climatic Conditions of Himachal Pradesh, India. In Proceedings of National Conference: Civil Engineering Conference-Innovation for Sustainability (CEC-2016) (Vol. 9, p. 10th).

George, B. A., Reddy, B. R. S., Raghuwanshi, N. S., \& Wallender, W. W. (2002). Decision support system for estimating reference evapotranspiration. Journal of Irrigation and Drainage Engineering, 128(1), 1-10. DOI: 10.1061/(ASCE) 0733-9437(2002)128:1(1) 
Gocic, M., \& Trajkovic, S. (2014). Analysis of trends in reference evapotranspiration data in a humid climate. Hydrological Sciences Journal, 59(1), 165-180.

Goroshi, S., Pradhan, R., Singh, R. P., Singh, K. K., \& Parihar, J. S. (2017). Trend analysis of evapotranspiration over India: Observed from long-term satellite measurements. Journal of Earth System Science, 126(8), 1-21.

Hamed, K. H. (2008). Trend detection in hydrologic data: The Mann-Kendall trend test under the scaling hypothesis. Journal of hydrology, 349(3-4), 350-363.

Hamed, K. H., \& Rao, A. R. (1998). A modified Mann-Kendall trend test for autocorrelated data. Journal of hydrology, 204(1-4), 182-196.

Heydari, M. M., Aghamajidi, R., Beygipoor, G., \& Heydari, M. (2014). Comparison and evaluation of 38 equations for estimating reference evapotranspiration in an arid region. Fresenius Environmental Bulletin, 23(8), 1985-1996.

Heydari, M. M., Noushabadi, R. N., Vahedi, M., Abbasi, A., \& Heydari, M. (2013). Comparison of evapotranspiration models for estimating reference evapotranspiration in arid environment. Mid. East $J$. Sci. Res, 15, 1331-7.

Jhajharia, D., DebBarma, S., \& Agrawal, G. (2004). Comparison of simpler radiation-based ET models with Penman Monteith model for humid region. Journal of Agricultural Engineering, 41(4), 32-36.

Jhajharia, D., Dinpashoh, Y., Kahya, E., Singh, V. P., \& Fakheri-Fard, A. (2012). Trends in reference evapotranspiration in the humid region of northeast India. Hydrological Processes, 26(3), 421-435.

Jhajharia, D., Kumar, R., Dabral, P. P., Singh, V. P., Choudhary, R. R., \& Dinpashoh, Y. (2015). Reference evapotranspiration under changing climate over the Thar Desert in India. Meteorological Applications, 22(3), 425-435.

Kashyap, P. S., \& Panda, R. K. (2001). Evaluation of evapotranspiration estimation methods and development of crop-coefficients for potato crop in a sub-humid region. Agricultural water management, 50(1), 9-25. DOI: 10.1016/S0378-3774(01)00102-0

Łabędzki L, Kanecka-Geszke E, Bak B, Slowinska S (2011) Estimation of reference evapotranspiration using the FAO Penman-Monteith method for climatic conditions of Poland Evapotranspiration: InTech. https://doi.org/10.5772/14081.

Leszek Łabedzki, Bogdan Bak, and Karolina Smarzyn'ska. Spatio-temporal variability and trends of penman-monteith reference evapotranspiration (fao-56) in 1971-2010 under climatic conditions of Poland. Polish Journal of Environmental Studies, 23(6):2083-2091, 2014. 
Li, Z., Zheng, F. L., \& Liu, W. Z. (2012). Spatiotemporal characteristics of reference evapotranspiration during 1961-2009 and its projected changes during 2011-2099 on the Loess Plateau of China. Agricultural and Forest Meteorology, 154, 147-155.

Liu CM. 2004. Study of some problems in water cycle changes of the Yellow River Basin. Advances in Water Science 15: 608-614 (in Chinese).

Liu XM, Zheng HX, Zhang MH, Liu CM (2011) Identification of dominant climate factor for pan evaporation trend in the Tibetan Plateau. J Geogr Sci 21(4):594-608

Liu, R., Wen, J., Wang, X., \& Wang, Z. (2017). Validation of evapotranspiration and its long-term trends in the Yellow River source region. Journal of Water and Climate Change, 8(3), 495-509.

Liu, X., \& Zhang, D. (2013). Trend analysis of reference evapotranspiration in Northwest China: the roles of changing wind speed and surface air temperature. Hydrological Processes, 27(26), 3941-3948.

Liu, Y., Wang, Q., Yao, X., Jiang, Q., Yu, J., \& Jiang, W. (2020). Variation in Reference Evapotranspiration over the Tibetan Plateau during 1961-2017: Spatiotemporal Variations, Future Trends and Links to Other Climatic Factors. Water, 12(11), 3178.

Lopes A, Saraiva J, Alcoforado MJ (2011) Urban boundary layer wind speed reduction in summer due to urban growth and environmental consequences in Lisbon. Environ Model Softw26:242-243

Lopez-Urrea, R., de Santa Olalla, F. M., Fabeiro, C., \& Moratalla, A. (2006). An evaluation of two hourly reference evapotranspiration equations for semiarid conditions. Agricultural water management, 86(3), 277-282.

Ma, Z. Z., Ray, R. L., \& He, Y. P. (2018). Assessing the spatiotemporal distributions of evapotranspiration in the Three Gorges Reservoir Region of China using remote sensing data. Journal of Mountain Science, 15(12), 2676-2692.

Mann, H. B. (1945). Nonparametric tests against trend. Econometrica: Journal of the econometric society, 245-259.

McVicar TR, Roderick ML (2010) Atmospheric science: winds of change. Nat Geosci 3(11):747-748

Murugappan, A., Subburayan, S., \& Mohan, S. (2011). Performance evaluation of calibrated Hargreaves method for estimation of Ref-ET in a hot and humid coastal location in India. International Journal of Engineering Science and Technology, 3(6).

Nandagiri, L., \& Kovoor, G. M. (2006). Performance evaluation of reference evapotranspiration equations across a range of Indian climates. Journal of irrigation and drainage engineering, 132(3), 238-249. DOI: 10.1061/(ASCE)0733-9437(2006)132:3(238) 
Ndiaye, P. M., Bodian, A., Diop, L., Deme, A., Dezetter, A., Djaman, K., \& Ogilvie, A. (2020). Trend and sensitivity analysis of reference evapotranspiration in the Senegal River basin using NASA meteorological data. Water, 12(7), 1957.

Chapter 23 Nonparametric Tests for Trend Detection, Editor(s): Keith W. Hipel, A. lan McLeod, Developments in Water Science, Elsevier, Volume 45, 1994, Pages 853-938, ISSN 0167-5648, ISBN 9780444892706

Pandey, A., \& Pandey, R. P. (2013). Analysing trends in reference evapotranspiration and weather variables in the Tons River Basin in Central India. Stochastic environmental research and risk assessment, 27(6), 1407-1421.

Pandey, P. K., Dabral, P. P., \& Pandey, V. (2016). Evaluation of reference evapotranspiration methods for the north eastern region of India. International Soil and Water Conservation Research, 4(1), 52-63. DOI:

10.1016/j.iswcr.2016.02.003

Poddar, A., Gupta, P., Kumar, N., Shankar, V., \& Ojha, C. S. P. (2018). Evaluation of reference evapotranspiration methods and sensitivity analysis of climatic parameters for sub-humid sub-tropical locations in western Himalayas (India). ISH Journal of Hydraulic Engineering, 1-11. DOI: $10.1080 / 09715010.2018 .1551731$

B. Singandhupe \& R. R. Sethi (2005) Estimation of reference evapotranspiration and crop coefficient in wheat under semi-arid environment in India, Archives of Agronomy and Soil Science, 51:6, 619-631, DOI: $10.1080 / 03650340500273831$

MOHAN (1991) Intercomparison of evapotranspiration estimates, Hydrological Sciences Journal, 36:5, 447-460, DOI: 10.1080/02626669109492530.

Sen PK (1968) Estimates of the regression coefficient based on Kendall's Tau. J Am Stat Assoc 63(324):1379-1389. doi:10.1080/01621459.1968.10480934

Shadmani, M., Marofi, S., \& Roknian, M. (2012). Trend analysis in reference evapotranspiration using Mann-Kendall and Spearman's Rho tests in arid regions of Iran. Water resources management, 26(1), 211224.

Singandhupe, R. B., \& Sethi, R. R. (2004). Computation of evapotranspiration by different methods. A case study. Ind J Soil Water Cons, 32(1), 5-9.

Soltani, E., \& Soltani, A. (2008). Climatic change of Khorasan, north-east of Iran, during 1950-2004. Res J Environ Sci, 2(5), 316-322.

Song, L., Zhuang, Q., Yin, Y., Zhu, X., \& Wu, S. (2017). Spatio-temporal dynamics of evapotranspiration on the Tibetan Plateau from 2000 to 2010. Environmental Research Letters, 12(1), 014011. 
Tabari, H., \& Talaee, P. H. (2011). Recent trends of mean maximum and minimum air temperatures in the western half of Iran. Meteorology and atmospheric physics, 111(3), 121-131.

Tabari, H., Grismer, M. E., \& Trajkovic, S. (2013). Comparative analysis of 31 reference evapotranspiration methods under humid conditions. Irrigation Science, 31(2), 107-117.

Tabari, H., Marofi, S., Aeini, A., Talaee, P. H., \& Mohammadi, K. (2011). Trend analysis of reference evapotranspiration in the western half of Iran. Agricultural and forest meteorology, 151(2), 128-136.

Tellen, V. A. (2017). A comparative analysis of reference evapotranspiration from the surface of rainfed grass in Yaounde, calculated by six empirical methods against the penman-monteith formula. Earth Perspectives, 4(1), 4.

Wang P, Yamanaka T, Qiu GY (2012a) Causes of decreased reference evapotranspiration and pan evaporation in the Jinghe River catchment, Northern China. Environmentalist 32:1 10

Wang WG, Shao QX, Peng SZ, Xing WQ, Yang T, Luo YF, Yong B, Xu JZ (2012b) Reference evapotranspiration change and the causes across the Yellow River Basin during 1957-2008 and their spatial and seasonal differences. Water Resour Res 48: W05530

Xie, H., \& Zhu, X. (2013). Reference evapotranspiration trends and their sensitivity to climatic change on the Tibetan Plateau (1970-2009). Hydrological Processes, 27(25), 3685-3693.

Xu CY, Gong L, Jiang T, Chen D, Singh VP (2006) Analysis of spatial distribution and temporal trend of reference evapotranspiration and pan evaporation in Changjiang (Yangtze River) catchment. J Hydrol $27: 81-93$

Yadav, D., Awasthi, M. K., \& Nema, R. K. (2017). Estimation of reference evapotranspiration using Aquacrop model for agro-climatic conditions of Madhya Pradesh. Indian Journal of Agricultural Research.

Yadav, S., Deb, P., Kumar, S., Pandey, V., \& Pandey, P. K. (2016). Trends in major and minor meteorological variables and their influence on reference evapotranspiration for mid Himalayan region at east Sikkim, India. Journal of Mountain Science, 13(2), 302-315.

Zeng, Z., Wu, W., Zhou, Y., Li, Z., Hou, M., \& Huang, H. (2019). Changes in reference evapotranspiration over Southwest China during 1960-2018: attributions and implications for drought. Atmosphere, 10(11), 705.

Zhang X, Ren Y, Yin ZY, Lin Z, Zheng D (2009) Spatial and temporal variation patterns of reference evapotranspiration across the Qinghai-Tibetan Plateau during 1971-2004. J Geophys Res 114: D15105. doi:10.1029/2009JD011753. 
Figures

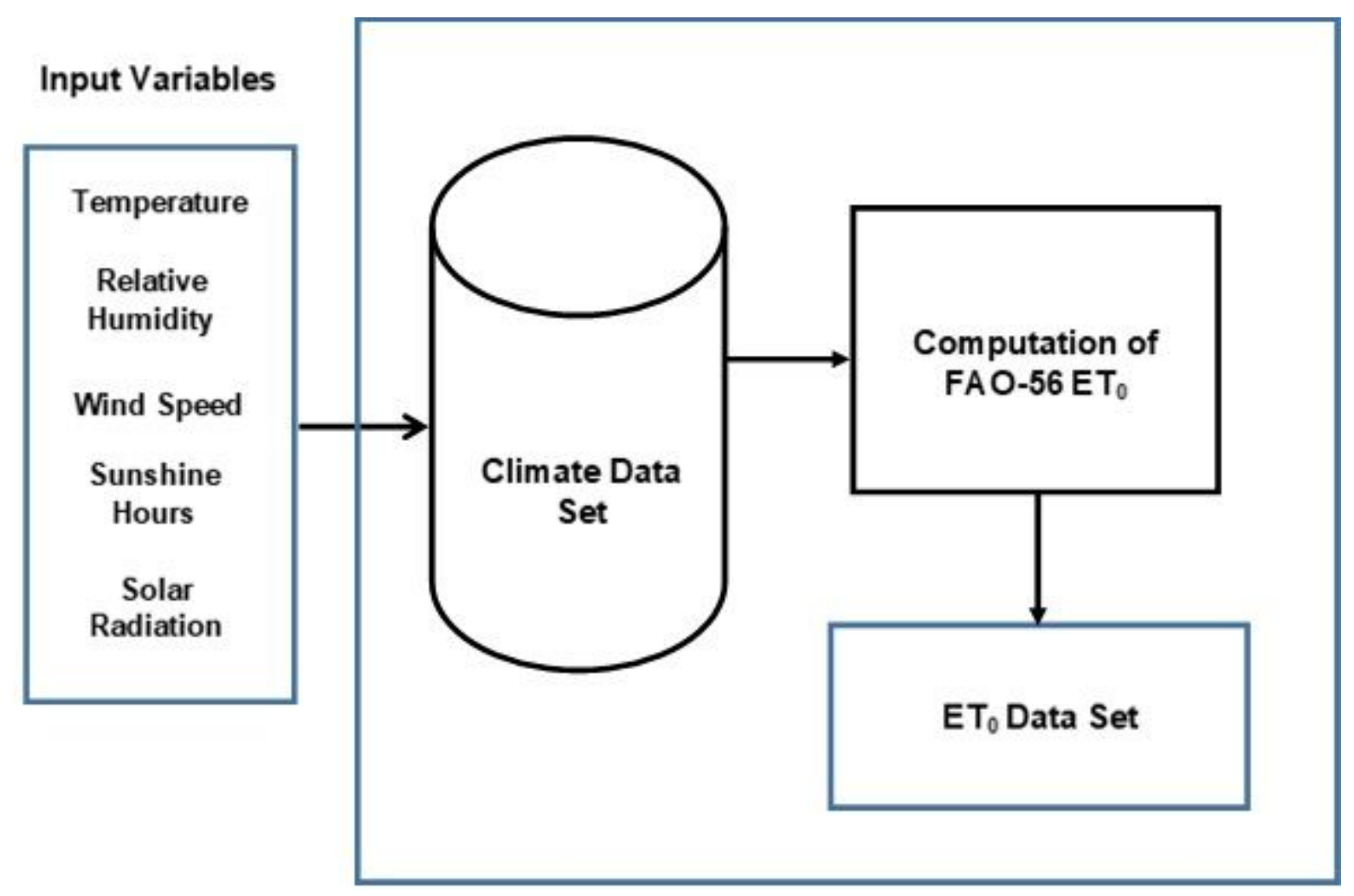

Figure 1

Computation of ETO from climate variables 

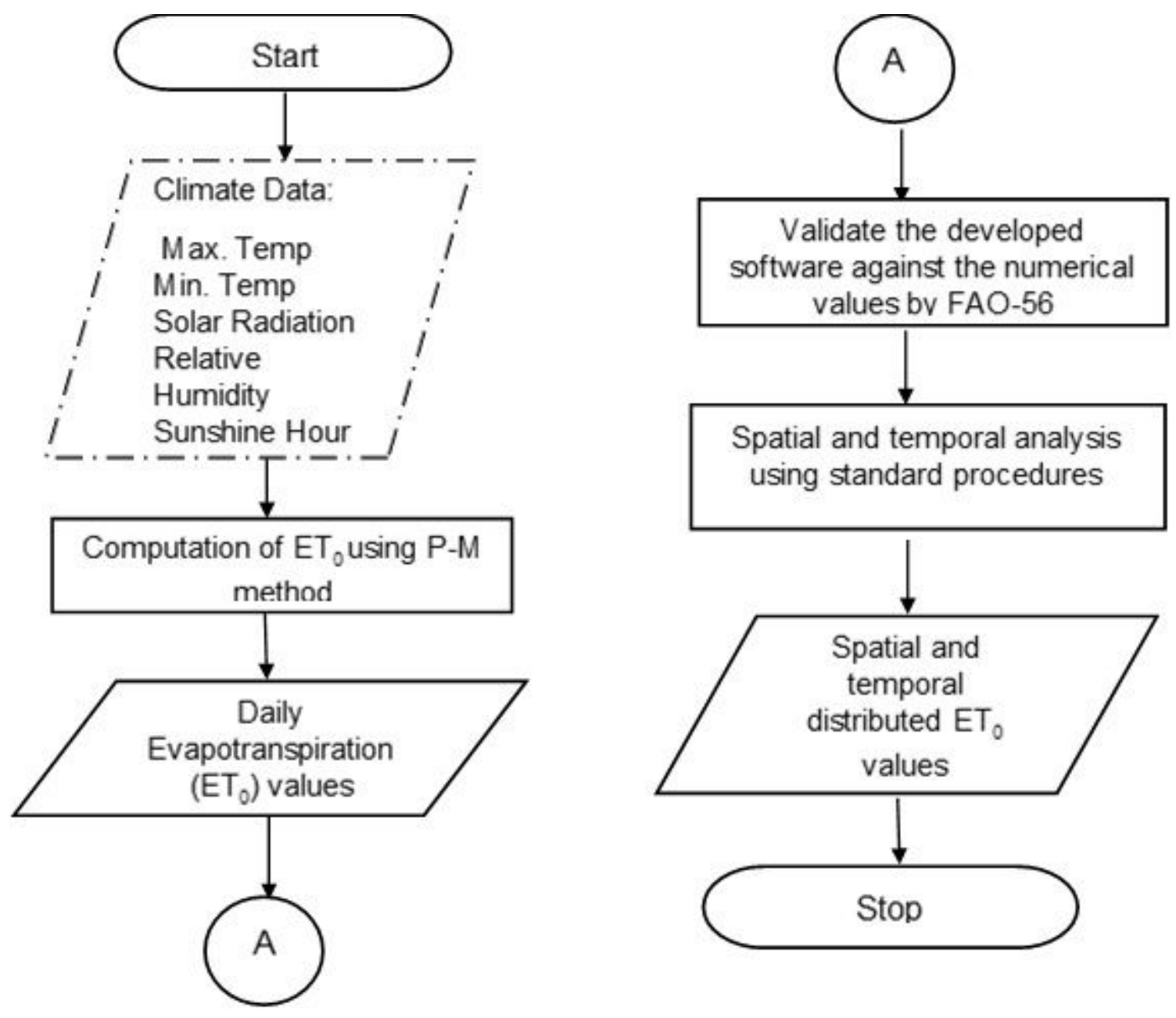

Figure 2

Flowchart of ETO computation 


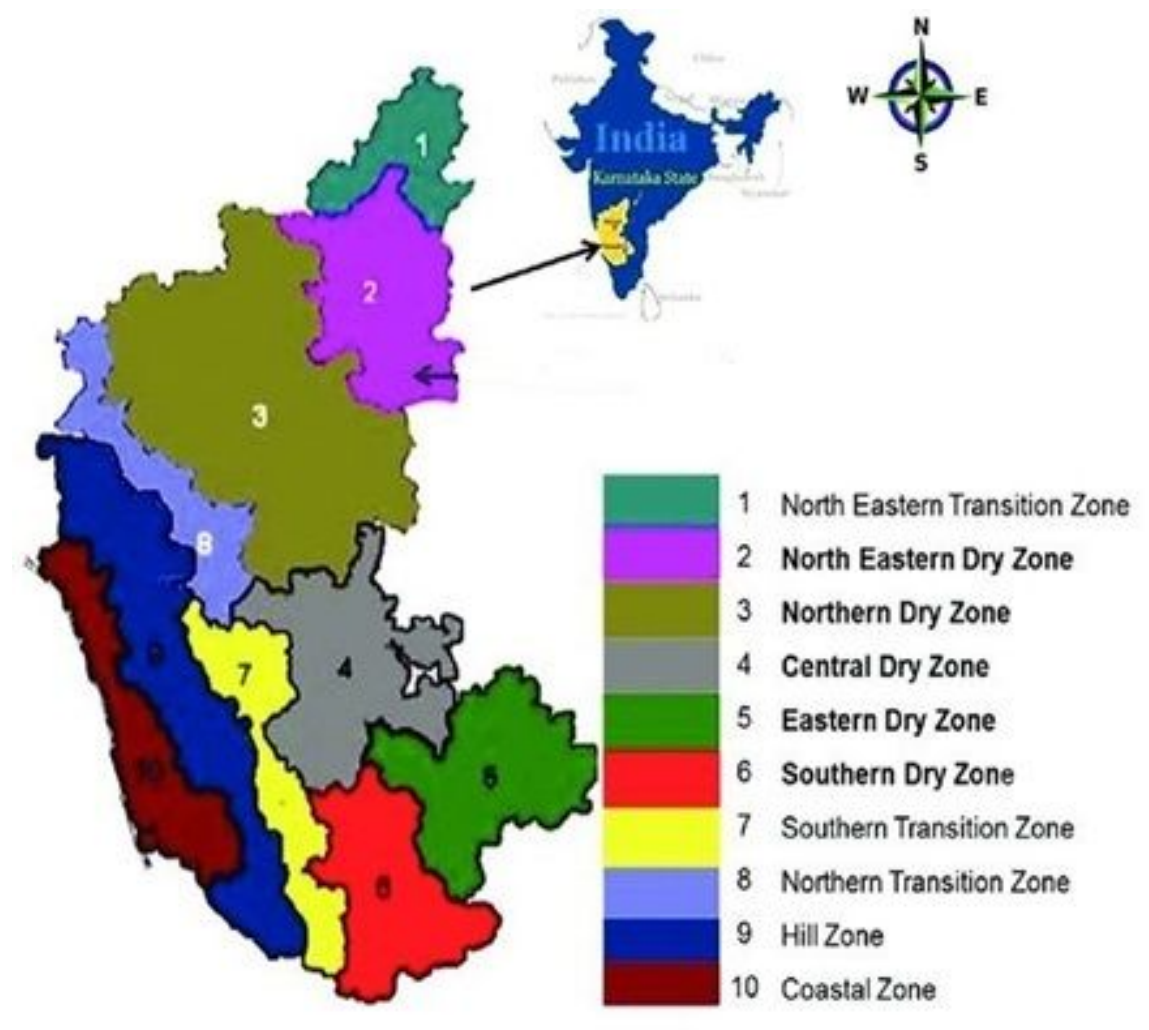

Figure 3

Karnataka Map showing its agro-climatic zones 


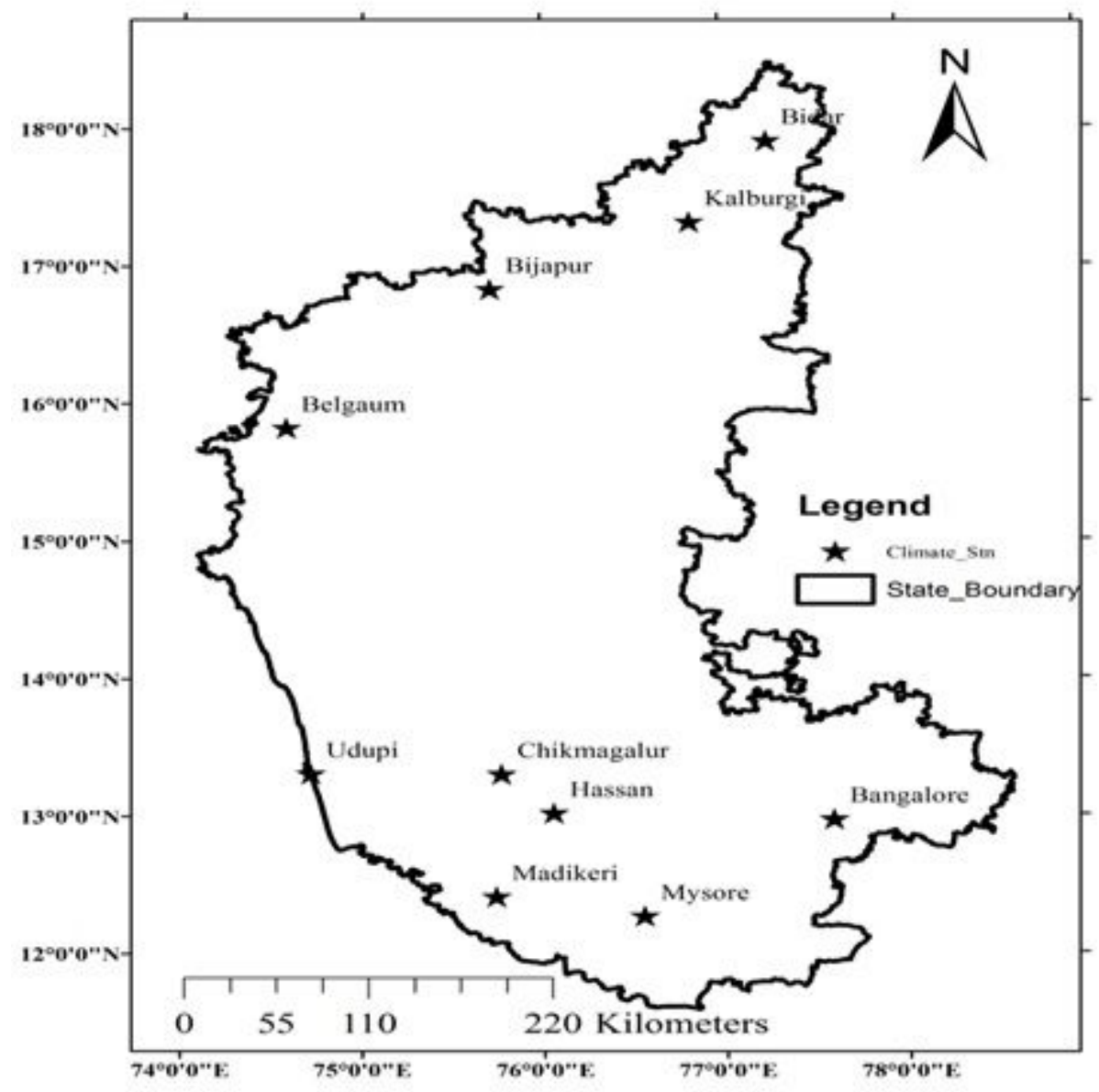

Figure 4

Geographical locations of the stations under study 


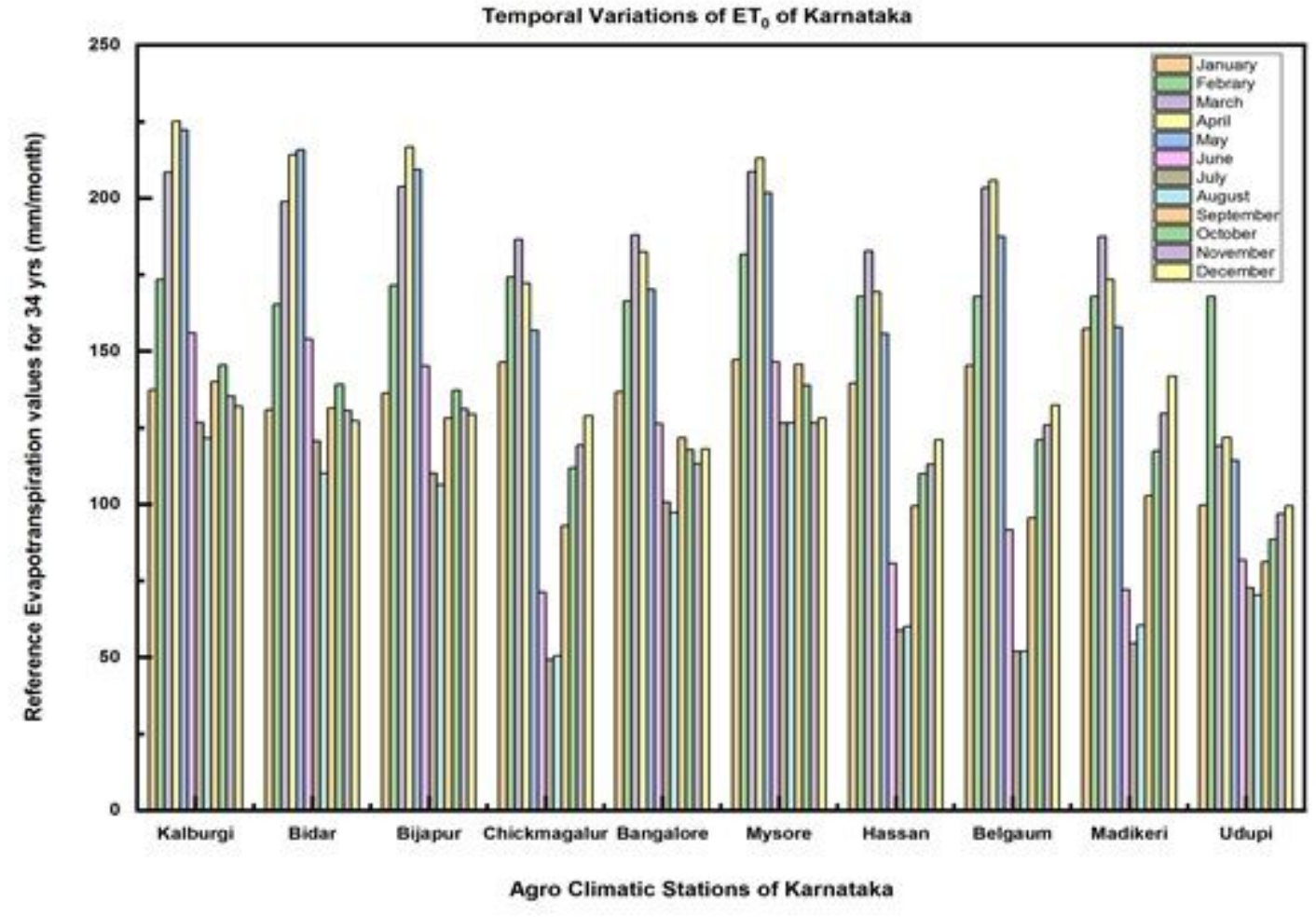

Figure 5

Average monthly ET0 of (a): Kalburgi (b): Bidar, (c): Bijapur, (d): Chikmagalur, (e): Bangalore, (f): Mysore, (g): Hassan, (h): Belgaum, (i): Madikeri, (j): Ududpi

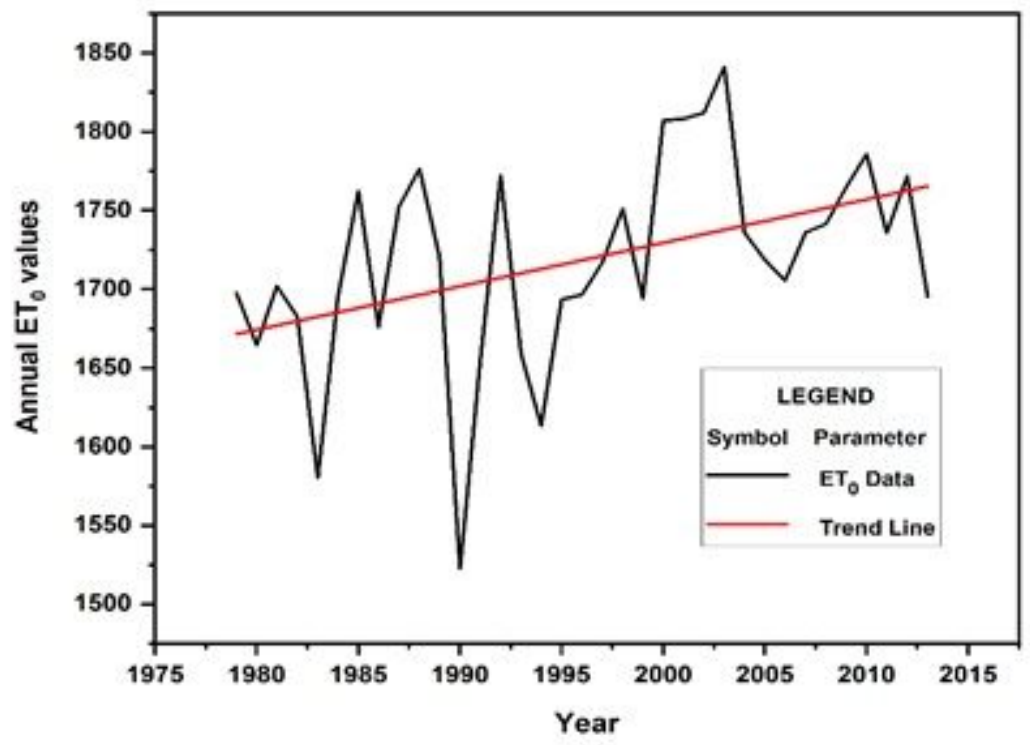

Figure 6

Annual ET0 variation at Kalburgi during the period 1979-2014 


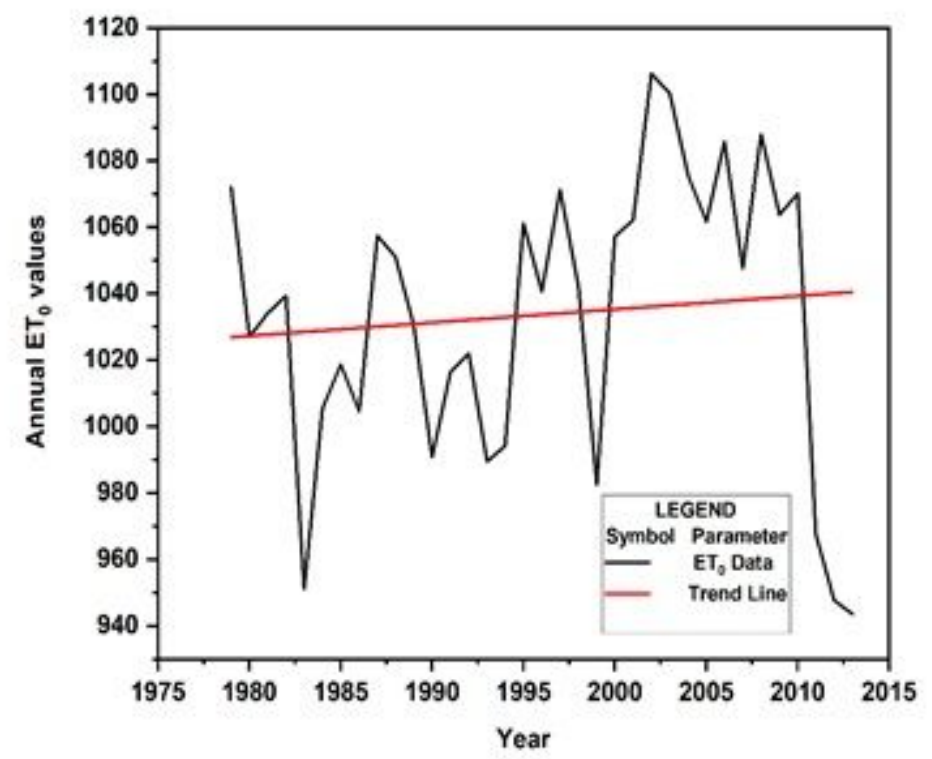

Figure 7

Annual ET0 variation at Udupi during the period 1979-2014

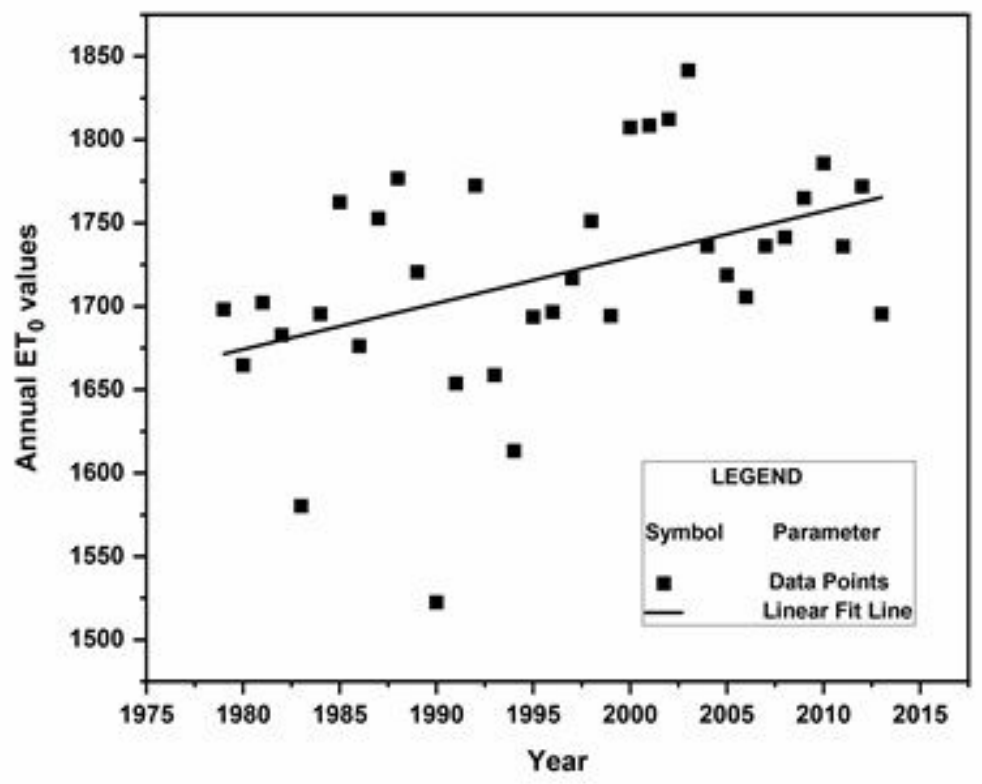

Figure 8

Sen's slope of annual ETO for Kalburgi 


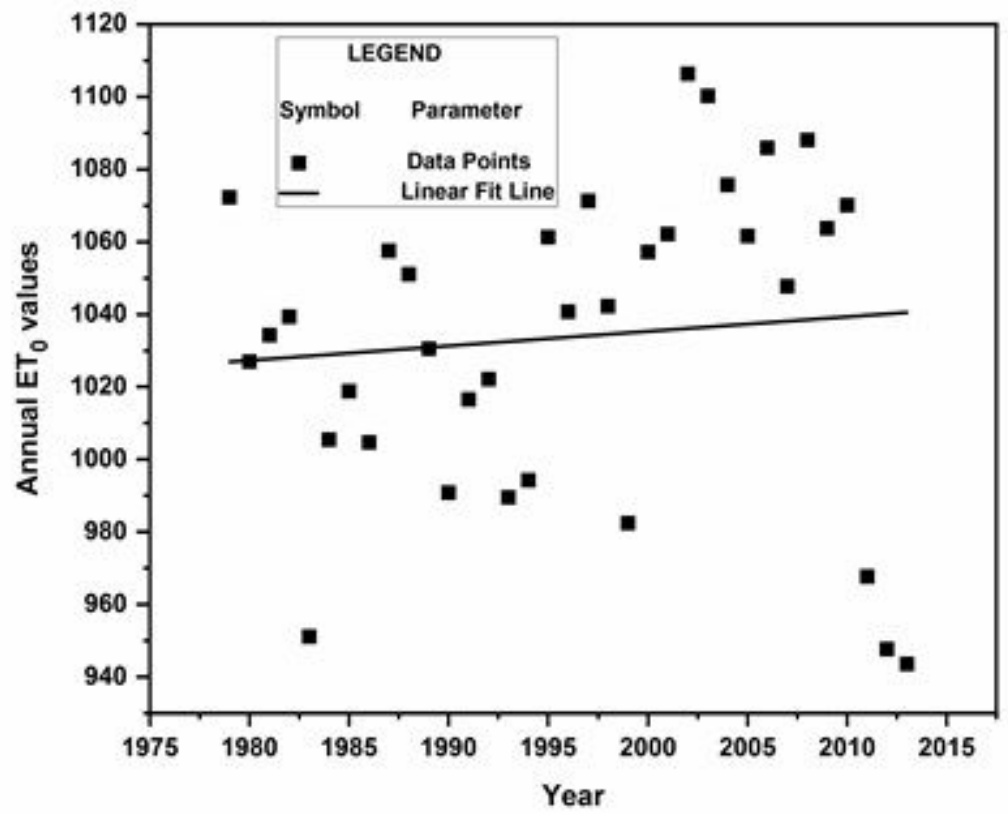

Figure 9

Sen's slope of annual ETO for Udupi

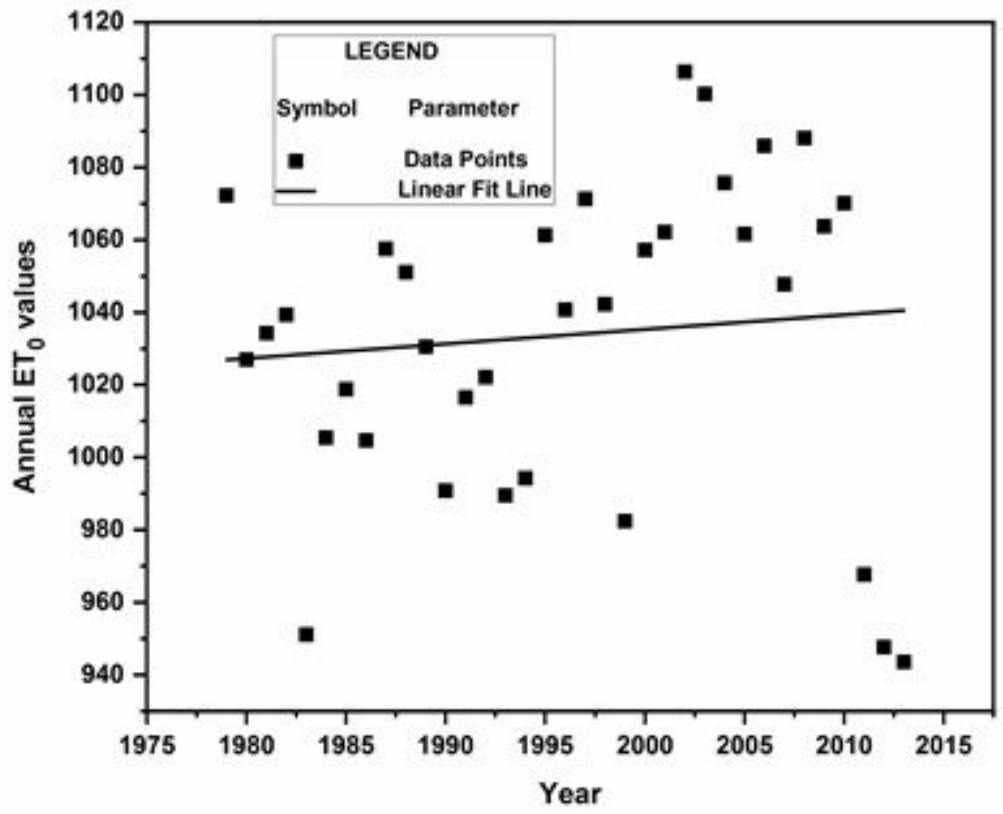

Figure 10

Mean annual temperature trend of Bidar 


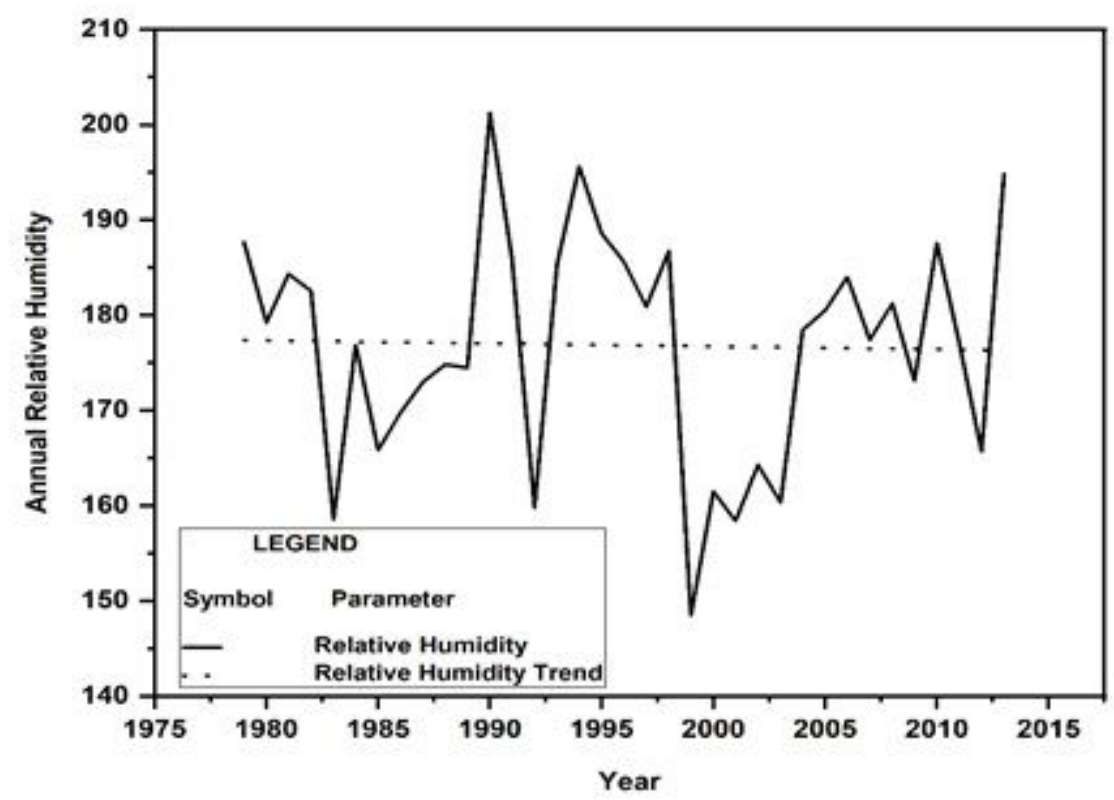

Figure 11

Annual relative humidity trend of Kalburgi

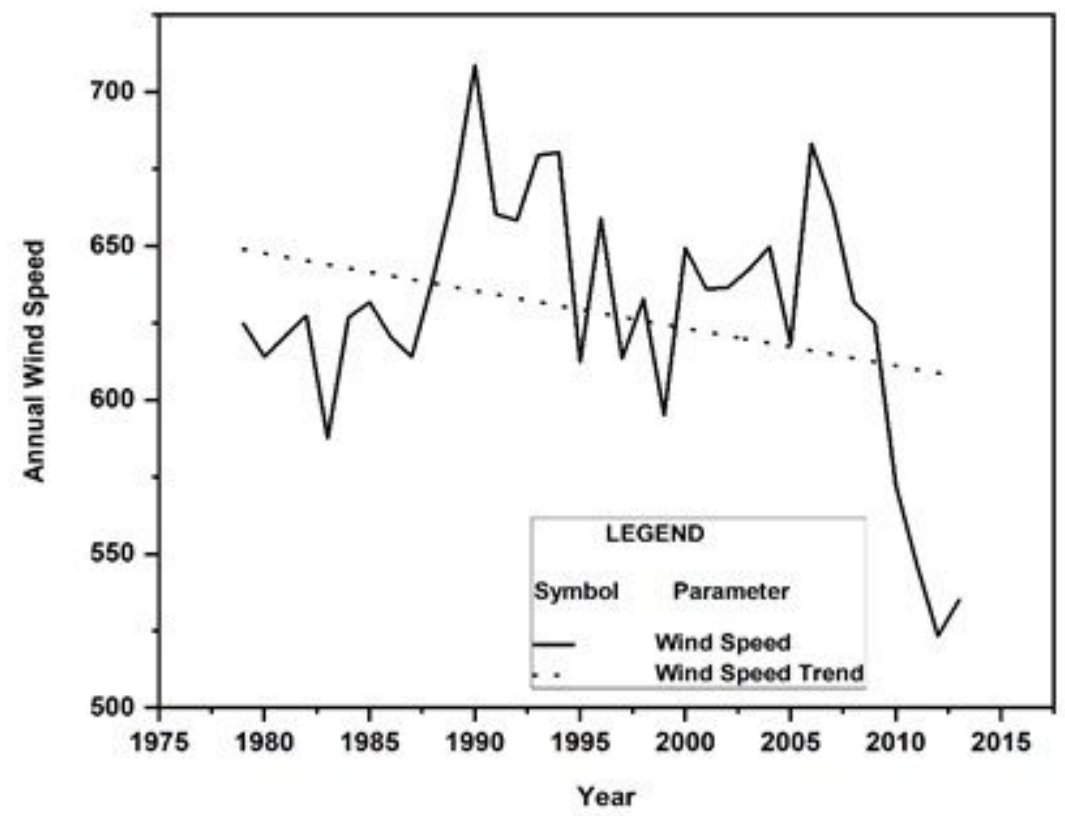

Figure 12

Annual wind speed Trend of Chikmagalur 


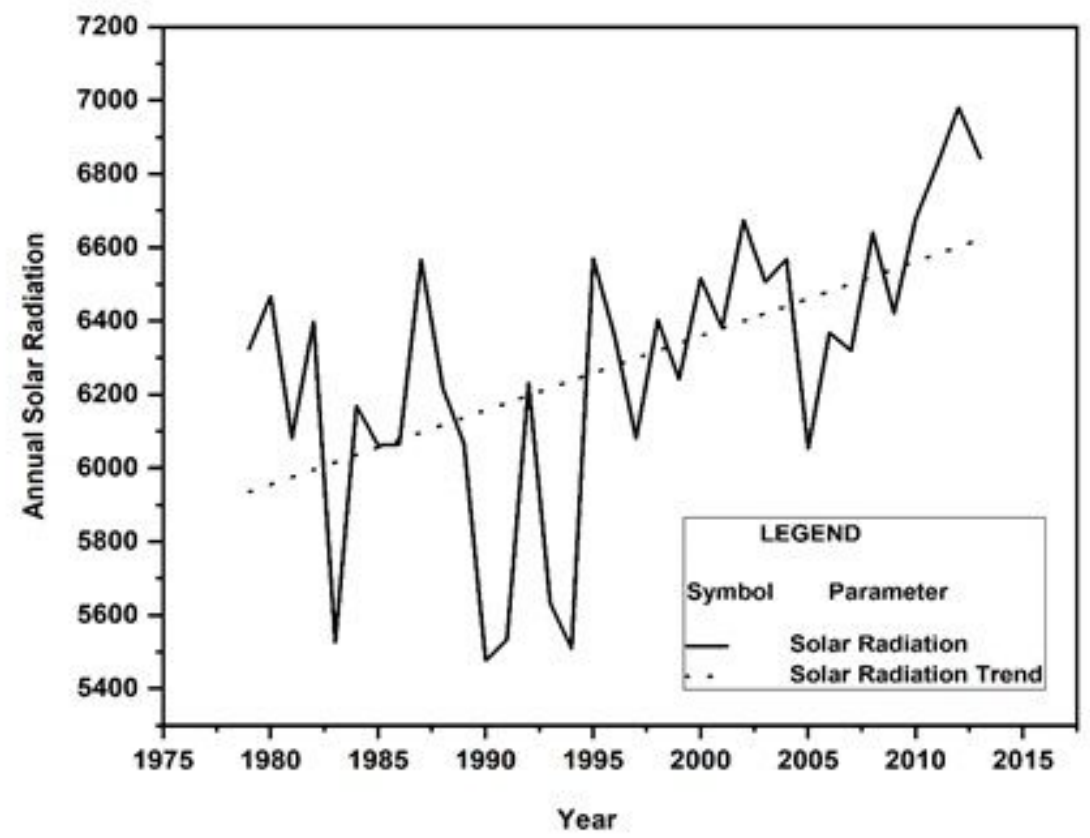

Figure 13

Annual solar radiation trend of Bangalore

\section{Supplementary Files}

This is a list of supplementary files associated with this preprint. Click to download.

- SupplementaryFile.docx 